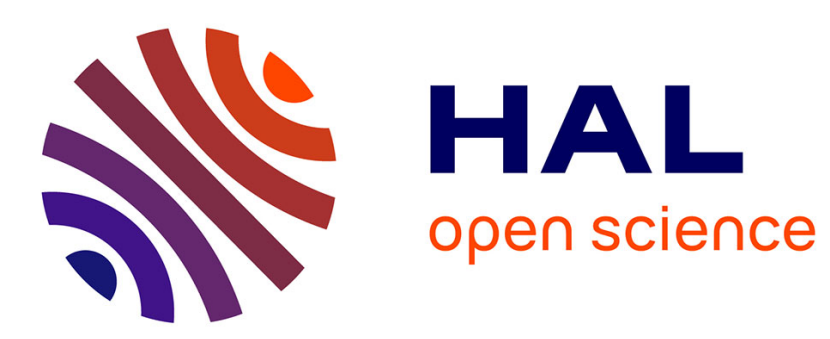

\title{
Paramagnetic Cobalt(II) Complexes with Cyclam Derivatives: Toward 19 F MRI Contrast Agents
}

Jan Blahut, Ladislav Benda, Jan Kotek, Guido Pintacuda, Petr Hermann

\section{To cite this version:}

Jan Blahut, Ladislav Benda, Jan Kotek, Guido Pintacuda, Petr Hermann. Paramagnetic Cobalt(II) Complexes with Cyclam Derivatives: Toward 19 F MRI Contrast Agents. Inorganic Chemistry, 2020, 59 (14), pp.10071-10082. 10.1021/acs.inorgchem.0c01216 . hal-03101302

\section{HAL Id: hal-03101302 https://hal.science/hal-03101302}

Submitted on 7 Jan 2021

HAL is a multi-disciplinary open access archive for the deposit and dissemination of scientific research documents, whether they are published or not. The documents may come from teaching and research institutions in France or abroad, or from public or private research centers.
L'archive ouverte pluridisciplinaire $\mathbf{H A L}$, est destinée au dépôt et à la diffusion de documents scientifiques de niveau recherche, publiés ou non, émanant des établissements d'enseignement et de recherche français ou étrangers, des laboratoires publics ou privés. 


\title{
Paramagnetic Cobalt(II) Complexes with Cyclam
}

\section{Derivatives: Towards ${ }^{19} \mathrm{~F}$ MRI Contrast Agents}

\author{
Jan Blahut, ${ }^{a b *}$ Ladislav Benda, ${ }^{b}$ Jan Kotek, ${ }^{a}$ Guido Pintacuda, ${ }^{b}$ Petr Hermann ${ }^{a *}$ \\ ${ }^{a}$ Department of Inorganic Chemistry (Faculty of Science, Charles University), Hlavova 2030, \\ 12843 Prague 2, Czech Republic. ${ }^{b}$ High-Field NMR Centre (CNRS FRE2034/UCB de Lyon \\ 1/ENS de Lyon), 5 rue de la Doua, 69100 Lyon-Villeurbanne, France.
}

KEYWORDS: paramagnetic NMR; high-spin cobalt complexes; macrocyclic complexes; phosphonate complexes; cyclam derivatives; kinetic inertness; hyperfine shift calculations; spin density delocalization; ${ }^{19} \mathrm{~F}$ MRI contrast agents; NMR relaxation

\begin{abstract}
In order to develop novel, more efficient and/or selective contrast agents for magnetic resonance imaging (MRI), different modi operandi are explored as alternatives to water-relaxation enhancement. In this work, cobalt(II/III) complexes of bis( $N$-trifluoroethy)cyclam derivatives with two acetate or two phosphonate pendant arms, $\mathrm{H}_{2}$ te2f $\mathbf{2 a}$ and $\mathrm{H}_{4} \mathbf{t e 2 f} \mathbf{2 p}$, were prepared and investigated. X-ray diffraction structures confirmed octahedral coordination with a very stable trans-III cyclam conformation and with fluorine atoms located about $5.3 \AA$ from the metal center. The $\mathrm{Co}(\mathrm{II})$ complexes are kinetically inert, decomposing slowly even in $1 \mathrm{M}$ aqueous $\mathrm{HCl}$ at $80{ }^{\circ} \mathrm{C}$. The $\mathrm{Co}(\mathrm{II})$ complexes exhibited well-resolved paramagnetically-shifted NMR spectra.
\end{abstract}


These were interpreted with the help of quantum chemistry calculations. The ${ }^{13} \mathrm{C}$ NMR shifts of the trans-[Co $\left.{ }^{\mathrm{II}}(\mathbf{t e 2 f} \mathbf{2} \mathbf{p})\right]$ complex were successfully assigned based on spin density delocalization within the ligand molecule. The obtained spin density also helps to describe $d$-metal-induced NMR relaxation properties of ${ }^{19} \mathrm{~F}$ nuclei, including the contribution of a Fermi contact relaxation mechanism. The paramagnetic complexes show convenient relaxation properties to be used as ${ }^{19} \mathrm{~F}$ MRI contrast agents.

\section{Introduction}

Complexes of $d$ - and $f$-elements with macrocyclic ligands are broadly used in diverse applications. Their stability/inertness, as well as reliably defined spectroscopic and magnetic properties, make them well-suited for utilization in medicine and molecular biology. ${ }^{1-7}$ The complexes of macrocyclic chelators are used in diagnostic medicine for various imaging modalities. The most common imaging techniques involve positron emission tomography (PET) with metal radioisotopes, as ${ }^{68} \mathrm{Ga},{ }^{64} \mathrm{Cu}$ or ${ }^{89} \mathrm{Zr}$, (Ref. 8) optical imaging with fluorescent lanthanide(III) ions ${ }^{6}$ and magnetic resonance imaging (MRI) employing complexes of trivalent gadolinium. ${ }^{1-5}$ Recently, complexes of metal ions other than Gd(III), e.g. divalent manganese or iron, have been investigated as contrast agents (CAs) for "classical" MRI based on imaging of water protons in tissues. ${ }^{9,10}$

For many prospective MRI applications, a highly quantitative response and "hot-spot" background-free information are required, in parallel with higher sensitivity of the MRI CAs to environmental changes in tissue. Several methods were developed including paramagnetic chemical exchange saturation transfer (PARACEST), ${ }^{11}$ detection of paramagnetically shifted ${ }^{1} \mathrm{H}$ nuclei present in the CAs (PARASHIFT) ${ }^{12-14}$ and utilization of ${ }^{19} \mathrm{~F} \cdot{ }^{15-18}$ These emerging CAs have mostly relied on paramagnetic lanthanide(III) ions while transition metal ions have been 
involved only very recently. The complexes of $d$-metal ions have been developed for application as PARACEST ${ }^{19-23}$ or PARASHIFT ${ }^{24}$ contrast agents and for ${ }^{19} \mathrm{~F}-\mathrm{MRI} .{ }^{25-28}$ The transition metal containing ${ }^{19} \mathrm{~F}$-MRI contrast agents have been used as responsive probes. ${ }^{18,22,29}$ The mostly utilized metal ions are divalent iron, cobalt or nickel.

Chemical, biochemical and magnetic properties of these complexes are often more favourable than those of more commonly utilized complexes of trivalent lanthanides. However, the relation between three-dimensional molecular structure, electronic structure and MRI CA efficiency of macrocyclic complexes is much less understood for transition metal ions than for trivalent lanthanides. The accessibility of reliable experimental data is, therefore, critical. Nuclear magnetic resonance spectroscopy (NMR) as the most versatile method for studying molecules in solution is used for paramagnetic systems as well (paramagnetic NMR, pNMR). ${ }^{30,31}$ In the MRI CA, however, the proximity of paramagnetic metal ion to the observed nucleus has an enormous impact on its NMR shift and relaxation properties. Due to these effects, coherence transfers are often not efficient and multidimensional correlation experiments are thus extremely difficult. Assignment and interpretation of large pNMR shifts relies therefore uniquely on 1D spectra and can be difficult or even impossible without additional information.

Such additional information is available from quantum chemistry (QC) modelling. Modern formulation $^{32,33}$ of Kurland-McGarvey theory of paramagnetically-induced shifts ${ }^{34}$ allows assignment and interpretation of pNMR spectra in systems with strong spin-orbit coupling such as Co(II) complexes. The pNMR shift calculations provide a direct link between the geometry of a transition metal complex, its electronic structure and the experimental NMR data. This synergistic pNMR/QC approach has recently been applied to Co(II) centers in small organometallic complexes ${ }^{35}$ and in metalloproteins. ${ }^{36}$ 
In this article, we characterize a series of paramagnetic Co(II) complexes in solution by a combination of NMR spectroscopy and theoretical calculations. Due to their promising chemical and relaxation properties, the studied complexes are proposed as new fluorine MRI CAs.

\section{Results and discussion}

\section{Complex synthesis and stability}

The ligands, $\mathrm{H}_{4}$ te2f2p and $\mathrm{H}_{2}$ te2f2a (Scheme 1), were obtained by published method. ${ }^{25,26}$ The macrocycle amine groups have to be deprotonated $\left(\log K_{1,2} 10.86\right.$ and 10.09) to allow their coordination and the final complex formation. ${ }^{25}$ It requires a high $\mathrm{pH}$ which causes precipitation of metal hydroxide in aqueous solution. Therefore, $\left[\mathrm{Co}\left(\mathrm{NH}_{3}\right)_{6}\right] \mathrm{Cl}_{2}$ in aqueous ammonia $(\sim 10 \%)$ was chosen as a cobalt source.

Scheme 1. Ligands discussed in this work.

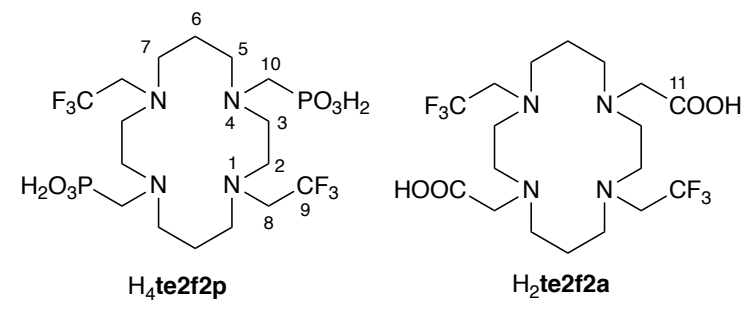

During the preparation of trans-[Co $\left.{ }^{\mathrm{II}}(\mathbf{t e 2 f 2 a})\right]$ (for depiction of isomers of cyclam complexes, see SI, Chart S1), an intermediate with ${ }^{19} \mathrm{~F}$ chemical shift $\delta_{\mathrm{F}}=-56.5 \mathrm{ppm}\left(\right.$ at $70{ }^{\circ} \mathrm{C}$ ) was observed immediately after reagent mixing and it slowly re-arranged into the final complex with $\delta_{\mathrm{F}}=-31.4 \mathrm{ppm}\left(\right.$ at $70{ }^{\circ} \mathrm{C}$; Figure S1) where the re-arrangement occurred mono-exponentially with an intermediate half-life $\tau_{1 / 2}=0.35 \mathrm{~h}$. A similar course for the complexation reaction was 


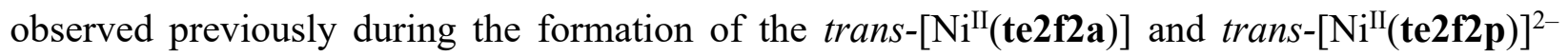
complexes, where a cis- $\mathrm{V}$ structure was suggested for the intermediate (see Chart $\mathrm{S} 1$ for the cyclam conformations in complexes $){ }^{25,26}$ The trans- $\left[\mathrm{Co}^{\mathrm{II}}(\mathbf{t e 2 f 2 p})\right]^{2-}$ complex was formed without any observable intermediate $\left(\tau_{1 / 2}=0.18 \mathrm{~h}\right.$ at $70{ }^{\circ} \mathrm{C}$; Figure S2). In water, the neutral

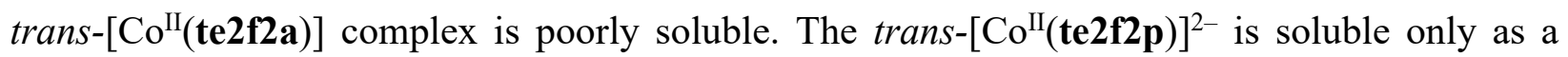
dianion at $\mathrm{pH}>6.5$.

Both complexes are exceptionally stable against acidic hydrolysis (Table S1). In $1 \mathrm{M}$ aq. $\mathrm{HCl}$ at $80{ }^{\circ} \mathrm{C}$, trans $-\left[\mathrm{Co}^{\mathrm{II}}(\mathbf{t e 2 f 2 a})\right]$ and trans- $\left[\mathrm{Co}^{\mathrm{II}}(\mathbf{t e 2 f 2 p})\right]^{2-}$ dissociate with half-life $\tau_{1 / 2}=0.53 \mathrm{~h}$ and $0.33 \mathrm{~h}$, respectively. With our best knowledge, we have not found any other cobalt(II) complexes decomposing so slowly at high temperature at $\mathrm{pH}$. The observed formation and dissociation kinetics as well as the solubility of these cobalt(II) complexes are related to those of their nickel(II) analogues which are, however, even more stable against hydrolysis (decomplexation $\tau_{1 / 2}$ values at $80{ }^{\circ} \mathrm{C}$ are $\sim 14$ days in $12 \mathrm{M}$ aq. $\mathrm{HCl}$ and $4.54 \mathrm{~h}$ in $1 \mathrm{M}$ aq. $\mathrm{HCl}$, for trans$\left[\mathrm{Ni}^{\mathrm{II}}(\mathbf{t e 2 f 2 a})\right]$ and trans-[Ni $\left.{ }^{\mathrm{II}}(\mathbf{t e 2} \mathbf{2} \mathbf{2})\right]^{2-}$, respectively). ${ }^{25,26}$ Such a large difference between the $\mathrm{Co}$ (II) and $\mathrm{Ni}$ (II) variants of the complex is expected, taking into account higher thermodynamic stabilization of the $\mathrm{d}^{8}$ electronic configuration compared to the $\mathrm{d}^{7}$ one according the IrvingWilliams series.

Counter-intuitively, the prepared cobalt(II) complexes are not sensitive to air oxygen, neither in the solid state nor in aqueous solution (no oxidation was observed within water potential window by cyclic voltametry). Such a resistance to oxidation has already been reported for several Co(II) complexes with macrocyclic ligands. ${ }^{37}$ To obtain diamagnetic trivalent cobalt complexes, solid meta-chloroperoxybenzoic acid ( $m$-CPBA) was used as an oxidant. The $m$ $\mathrm{CPBA}$ is insoluble in water and, thus, the reaction was performed heterogeneously with the 
added advantage that excess $m$-CPBA and products of its reduction are easily removed by filtration. It should be noted that decomposition of the ligand (te2f2p $)^{4-}$ was observed when the oxidation was carried out with hydrogen peroxide instead of $m$-CPBA. Cleavage of the C-P bond in the $\mathrm{N}-\mathrm{C}-\mathrm{P}$ fragment has been reported under such conditions. ${ }^{38}$ Both trans$\left[\mathrm{Co}^{\mathrm{III}}(\mathbf{t e 2 f 2 a})\right]^{+}$and trans $-\left[\mathrm{Co}^{\mathrm{III}}(\mathbf{t e 2 f} \mathbf{2 p})\right]^{-}$complexes were later used as diamagnetic standards for calculations of NMR shift and relaxation.

\section{Solid-state structures of the complexes}

Molecular structures of individual complexes (Figures 1-3) were unambiguously confirmed by single-crystal X-ray diffraction (XRD, Table S2). The parameters of the coordination spheres are outlined in Table 1. In the solid state, all complexes have trans arrangement of the pendant arms and conformation III of the macrocyclic ring (for definition of the macrocycle stereochemistry, see Chart S1 and Ref. 39). The complex anions found in trans-[Co $\left.{ }^{\mathrm{II}}(\mathbf{t e 2 f 2 a})\right] \cdot 2 \mathrm{MeOH}$ and $\left(\mathrm{NH}_{4}\right)\left\{\right.$ trans $\left.-\left[\mathrm{Co}{ }^{\mathrm{III}}(\mathbf{t e 2 f} 2 \mathbf{p})\right]\right\} \cdot 11 \mathrm{H}_{2} \mathrm{O}$ possess a centre of symmetry. The coordination distances correspond with the oxidation state of the central cobalt ion. The metal-donor atom distances in the divalent ion complexes, trans $-\left[\mathrm{Co}^{\mathrm{II}}(\mathbf{t e 2 f 2 a})\right]$ and $\operatorname{trans}-\left[\mathrm{Co}^{\mathrm{II}}(\mathrm{Hte2f2p})\right]^{-}$, are longer by $0.1-$ $0.2 \AA$ than the analogous distances in the trivalent ion complex. Axially coordinated oxygen atoms are the closest donors while the longest coordination bonds are those of the nitrogen atoms bearing the 2,2,2-trifluoroethyl due to a low nucleophilicity of these amino groups. Coordination bonds of the nitrogen atoms bearing axially coordinating pendant arms are about $0.1 \AA$ shorter compared to those of $N$-trifluoroethyl as a result of their higher nucleophilicity and coordination stabilization through formation of the axial chelate ring. This feature is consistent with the data

previously observed for the analogous Ni(II) complexes. ${ }^{26}$ The octahedral shape of all complexes 
is only negligibly distorted, mainly due to steric demands of the chelate rings formed by the macrocycle amino groups, with the $\mathrm{N}-\mathrm{Co}-\mathrm{O}$ angles of the five-membered rings and the $\mathrm{N}-\mathrm{Co}-\mathrm{N}$ angles of the six-membered rings only slightly deviating from $90^{\circ}$. The average Co $\cdots \mathrm{F}$ distances (Table 1) in the $\mathrm{Co}^{\mathrm{II}}$ complexes, a crucial parameter for the ${ }^{19} \mathrm{~F}$ relaxation enhancement, are 5.24 and $5.26 \AA$ complexes with acetate- and phosphonate-containing ligands, respectively. The parameters are similar to those observed previously for the $\mathrm{Ni}(\mathrm{II})$ analogues $(5.22-5.23 \AA) .{ }^{26}$ The average $\mathrm{Co} \cdots \mathrm{F}$ distance in the $\mathrm{Co}{ }^{\mathrm{III}}$ complex, $5.14 \AA$, is slightly shorter than those found in the divalent metal ion complexes.

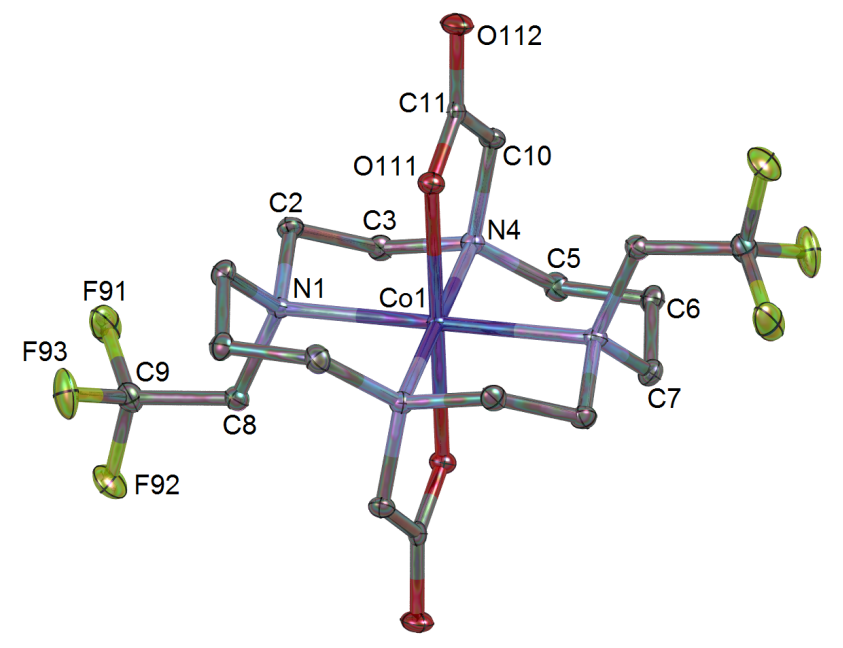

Figure 1. Molecular structure of trans-[CoI $(\mathbf{t e 2 f 2 a})]$ complex found in the crystal structure of trans-[Co $\left.{ }^{\mathrm{II}}(\mathbf{t e 2 f 2 a})\right] \cdot 2 \mathrm{MeOH}$. Hydrogen atoms are omitted for clarity.

In the structure of the trans- $\left[\mathrm{Co}^{\mathrm{II}}(\mathrm{Hte2f2p})\right]^{-}$anion, one of the $\mathrm{P}-\mathrm{O}$ distances is longer, indicating protonation of the corresponding uncoordinated oxygen atom $[d(\mathrm{P}-\mathrm{O} 12 \mathrm{~A})=1.568 \AA]$ whereas the distances to the other uncoordinated oxygen atoms are significantly shorter $[d(\mathrm{P}-\mathrm{O})$ $=1.503-1.536 \AA]$ pointing to a phosphoryl $(\mathrm{P}=\mathrm{O})$ character of these bonds (Figure 2). The 
oxygen atom $\mathrm{O} 12 \mathrm{~A}$ is protonated and the corresponding hydrogen atom was fully refined. It is stabilized by a short hydrogen bond to oxygen atom O12B\# from the neighboring molecule: $d(\mathrm{O} 12 \mathrm{~A}-\mathrm{H} 12 \mathrm{~A}) \quad 0.96, d(\mathrm{H} 12 \mathrm{~A} \cdots \mathrm{O} 12 \mathrm{~B} \#) \quad 1.51, d(\mathrm{O} 12 \mathrm{~A} \cdots \mathrm{O} 12 \mathrm{~B} \#) \quad 2.468 \AA$ and $\angle(\mathrm{O} 12 \mathrm{~A}-$ H12A $\cdots \mathrm{O} 12 \mathrm{~B} \#) 177^{\circ}$. The hydrogen bond slightly elongates also P1B-O12B bond to $1.536 \AA$ comparing to the remaining ones. The monoprotonated coordinated ligand (Hte2f2p $)^{3-}$ was also found in the structure of the analogous $\mathrm{Ni}$ (II) $\operatorname{complex}^{26}$ as well as in some complexes of divalent metal ions with several methylphosphonate cyclam derivatives. ${ }^{40}$ Analogous distances found in the structure of the trans-[Co $\left.{ }^{\mathrm{III}}(\mathbf{t e 2 f} 2 \mathbf{p})\right]^{-}$anion are all in the range $d(\mathrm{P}-\mathrm{O})=1.510-1.511 \AA$, clearly pointing to a full deprotonation (Figure 3).

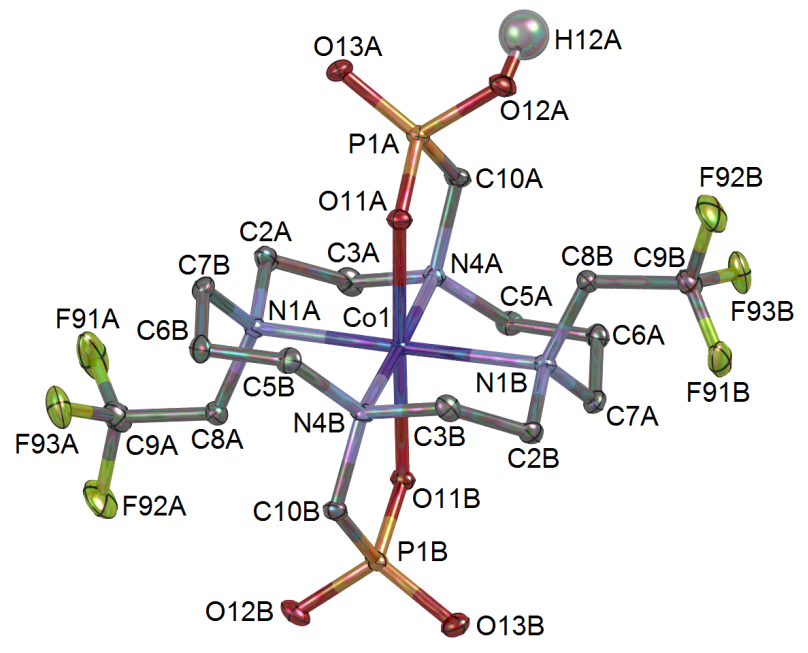

Figure 2. Molecular structure of trans-[Co $\left.{ }^{\mathrm{II}}(\mathrm{Hte2f2p})\right]^{-}$anion found in the crystal structure of $\left(\mathrm{NH}_{4}\right)\left\{\right.$ trans- $\left.\left[\mathrm{Co}{ }^{\mathrm{II}}(\mathrm{Hte} 2 \mathrm{f} 2 \mathrm{p})\right]\right\} \cdot 3.5 \mathrm{H}_{2} \mathrm{O}$. Carbon-bound hydrogen atoms are omitted for clarity. 


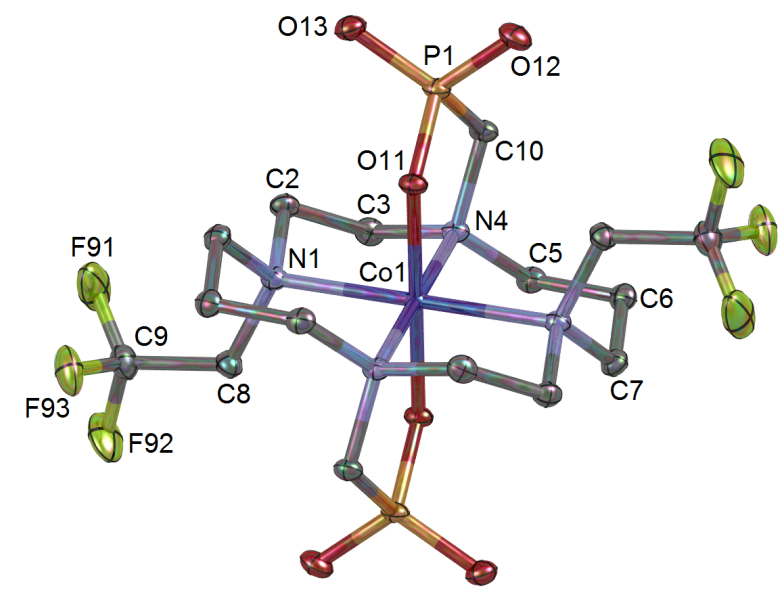

Figure 3. Molecular structure of trans-[Co $\left.\mathrm{Co}^{\mathrm{III}}(\mathbf{t e 2 f 2 p})\right]^{-}$anion found in the crystal structure of $\left(\mathrm{NH}_{4}\right)\left\{\right.$ trans $\left.-\left[\mathrm{Co}^{\mathrm{III}}(\mathbf{t e 2 f} \mathbf{2 p})\right]\right\} \cdot 11 \mathrm{H}_{2} \mathrm{O}$. Hydrogen atoms are omitted for clarity.

Table 1. Selected geometric parameters found in crystal structures of the studied complexes.

\begin{tabular}{|c|c|c|c|}
\hline Parameter & $\begin{array}{l}\text { trans- } \\
{\left[\mathrm{Co}^{\mathrm{II}}(\mathbf{t e 2 f 2 a})\right] \cdot 2 \mathrm{MeOH}^{a}}\end{array}$ & $\begin{array}{l}\left(\mathrm{NH}_{4}\right)\left\{\text { trans }^{-}\right. \\
\left.\left[\mathrm{Co}^{\mathrm{II}}(\mathrm{Hte} \mathbf{f} 2 \mathbf{p})\right]\right\} \cdot 3.5 \mathrm{H}_{2} \mathrm{O}\end{array}$ & $\begin{array}{l}\left(\mathrm{NH}_{4}\right)\{\text { trans- } \\
\left.\left[\mathrm{Co}^{\mathrm{III}}(\mathbf{t e 2 f} \mathbf{2 p})\right]\right\} \cdot 11 \mathrm{H}_{2} \mathrm{O}^{a}\end{array}$ \\
\hline \multicolumn{4}{|c|}{ Bond lengths $(\AA)$} \\
\hline $\mathrm{Co}-\mathrm{O} 11 \mathrm{~A}$ & $2.054(1)$ & $2.071(2)$ & $1.896(1)$ \\
\hline $\mathrm{Co}-\mathrm{O} 11 \mathrm{~B}$ & $2.054(1)$ & $2.106(2)$ & $1.896(1)$ \\
\hline $\mathrm{Co}-\mathrm{N} 1 \mathrm{~A}$ & $2.252(1)$ & $2.253(2)$ & $2.125(1)$ \\
\hline $\mathrm{Co}-\mathrm{N} 4 \mathrm{~A}$ & $2.117(1)$ & $2.147(2)$ & $2.009(1)$ \\
\hline Co-N1B & $2.252(1)$ & $2.256(2)$ & $2.125(1)$ \\
\hline $\mathrm{Co}-\mathrm{N} 4 \mathrm{~B}$ & $2.117(1)$ & $2.129(2)$ & $2.009(1)$ \\
\hline Average Co $\cdots \mathrm{F}$ & 5.26 & 5.24 & 5.14 \\
\hline
\end{tabular}

Bond angles $\left(^{\circ}\right)$

\begin{tabular}{llll}
\hline O11A-Co-O11B & 180 & $176.54(7)$ & 180
\end{tabular}




$\begin{array}{llll}\text { O11A-Co-N1A } & 89.68(5) & 91.01(7) & 89.72(4) \\ \text { O11A-Co-N4A } & 81.89(5) & 85.53(7) & 89.53(4) \\ \text { O11A-Co-N1B } & 90.32(5) & 88.44(7) & 90.27(4) \\ \text { O11A-Co-N4B } & 98.11(5) & 92.56(7) & 90.48(4) \\ \text { O11B-Co-N1A } & 90.32(5) & 91.36(7) & 90.27(4) \\ \text { O11B-Co-N4A } & 98.11(5) & 97.20(7) & 90.48(4) \\ \text { O11B-Co-N1B } & 89.68(5) & 89.21(7) & 89.72(4) \\ \text { O11B-Co-N4B } & 81.89(5) & 84.75(7) & 89.53(4) \\ \text { N1A-Co-N4A } & 85.87(5) & 84.67(7) & 87.42(4) \\ \text { N1A-Co-N1B } & 180 & 179.19(7) & 180 \\ \text { N1A-Co-N4B } & 94.13(5) & 94.30(7) & 92.58(4) \\ \text { N4A-Co-N1B } & 94.13(5) & 94.70(7) & 92.58(4) \\ \text { N4A-Co-N4B } & 180 & 177.81(8) & 180 \\ \text { N1B-Co-N4B } & 85.87(5) & 86.32(7) & 87.42(4)\end{array}$

${ }^{a}$ For centrosymmetric molecules: N1B = N1\#, N4B = N4\#, O11B = O11\#; \# means symmetryrelated atoms.

\section{Magnetometry and paramagnetic NMR spectroscopy}

According to the bulk magnetic susceptibility measurement of a trans-[Co $\left.{ }^{\mathrm{II}}(\mathbf{t e 2 f 2 p})\right]^{2-}$ solution, the complex is indeed paramagnetic with an effective magnetic moment $\mu_{\mathrm{eff}}=4.9(2) \mu_{\mathrm{B}}$ (units of Bohr magneton). Comparing with the spin-only magnetic moment $\mu_{\text {spin-only }}=g_{\mathrm{e}}[\mathrm{S}(\mathrm{S}+$ 1) $]^{1 / 2} \mu_{\mathrm{B}}=3.88 \mu_{\mathrm{B}}$, it is clear that the orbital contribution due to the spin-orbit coupling is important in this complex. The measured value of the effective magnetic moment confirms a high-spin $\mathrm{d}^{7}$ configuration, as it falls close to the common $\mu_{\text {eff }}$ range $4.8-5.2 \mu_{\mathrm{B} .}{ }^{41}$

Given the high magnetic moment of the central cobalt(II) ion, a strong paramagnetic broadening of the NMR signals was expected to negatively impact the spectral resolution and to 
leave any $J$-coupling pattern indistinguishable. Surprisingly, in our case, well-resolved ${ }^{1} \mathrm{H}$ (Figure 4) and ${ }^{19} \mathrm{~F}$ NMR (Figure 5) spectra of trans- $\left[\mathrm{Co}^{\mathrm{II}}(\mathbf{t e 2 f 2 a})\right]$ and trans- $\left[\mathrm{Co}^{\mathrm{II}}(\mathbf{t e 2 f 2 p})\right]^{2-}$, and a ${ }^{13} \mathrm{C}$ NMR spectrum of trans-[Co $\left.\mathrm{Co}^{\mathrm{II}}(\mathbf{t e 2 f} \mathbf{2 p})\right]^{2-}$ (Figure 6) complexes were obtained (while a ${ }^{13} \mathrm{C}$ NMR spectrum of trans-[Co $\left.{ }^{\mathrm{II}}(\mathbf{t e 2 f 2 a})\right]$ could not be obtained within reasonable experimental time due to low solubility of the complex).
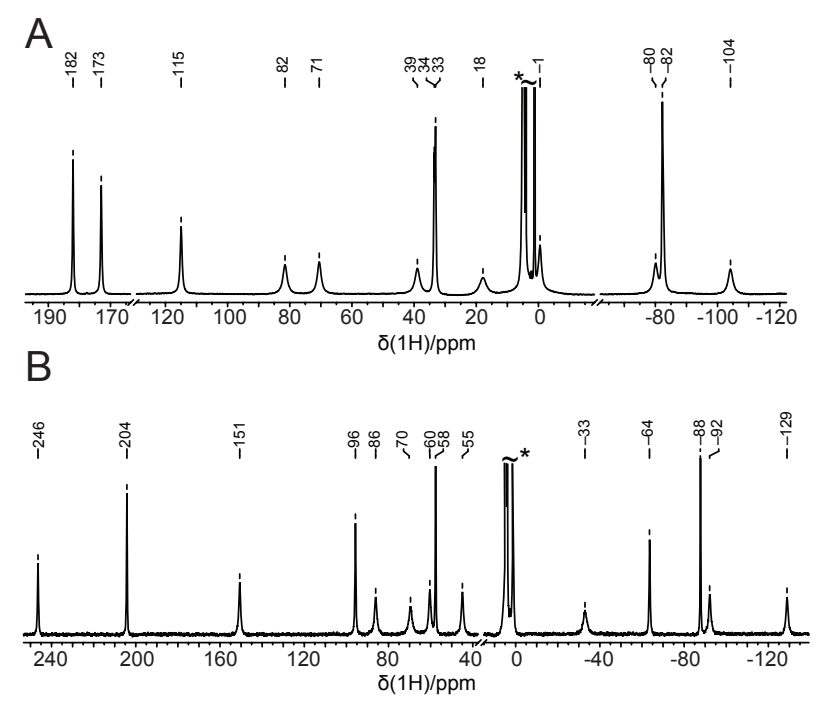

Figure 4. ${ }^{1} \mathrm{H}$ NMR $\left(300 \mathrm{MHz}, \mathrm{D}_{2} \mathrm{O}\right)$ spectra of $(\mathbf{A})$ trans- $\left[\mathrm{Co}^{\mathrm{II}}(\mathbf{t e 2 f 2 p})\right]^{2-}(\mathrm{pD} 10.9)$ and $(\mathbf{B})$ trans-[Co $\left.{ }^{\mathrm{II}}(\mathbf{t e 2 f 2 a})\right]$ (pD 9.2). Solvent and shift-reference signals ( $t$-BuOH and TFE) are labelled with an asterisk. Concentration of $\sim 10 \mathrm{mg} / \mathrm{ml}$ was used in (A), while in (B), the low solubility of trans-[Co $\left.{ }^{\mathrm{II}}(\mathbf{t e 2 f 2 a})\right]$ limits the concentration to approx. $1 \mathrm{mg} / \mathrm{ml}$.

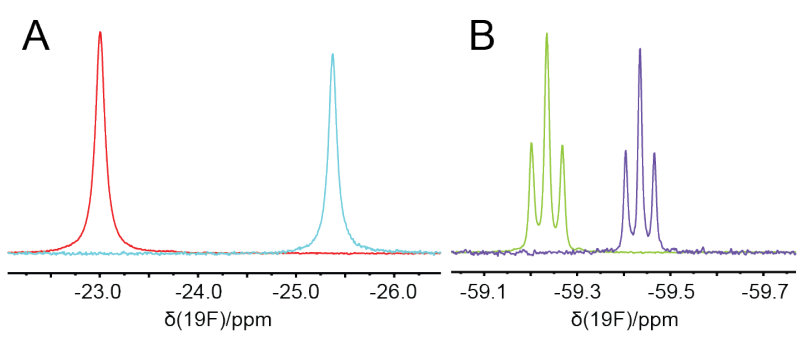


Figure 5. ${ }^{19} \mathrm{~F}$ NMR spectra $\left(282 \mathrm{MHz}, \mathrm{D}_{2} \mathrm{O}, \mathrm{pD} 7\right)$ of (A) paramagnetic trans-[Co $\left.{ }^{\mathrm{II}}(\mathbf{t e 2 f} \mathbf{2})\right]^{2-}$ (red) and trans-[Co $\left.{ }^{\mathrm{II}}(\mathbf{t e 2 f 2 a})\right]$ (blue), and (B) diamagnetic trans-[Co $\left.{ }^{\mathrm{III}}(\mathbf{t e 2 f 2 p})\right]^{-}$(green) and trans-[CoIII (te2f2a) $]^{+}$(violet) complexes. Spectra were obtained with 44 (A, trans$\left[\mathrm{Co}^{\mathrm{II}}\left(\text {te2f2p}^{2}\right]^{2-}\right), 256$ (A, trans-[Co $\left.\left.{ }^{\mathrm{II}}(\mathbf{t e 2 f 2 a})\right]\right)$ and 16 (both spectra in B) scans with concentration $\sim 10 \mathrm{mg} / \mathrm{ml}$, except trans-[Co $\left.{ }^{\mathrm{II}}(\mathbf{t e 2 f 2 a})\right]$ where concentration was limited by solubility of the complex to approx. $1 \mathrm{mg} / \mathrm{ml}$.
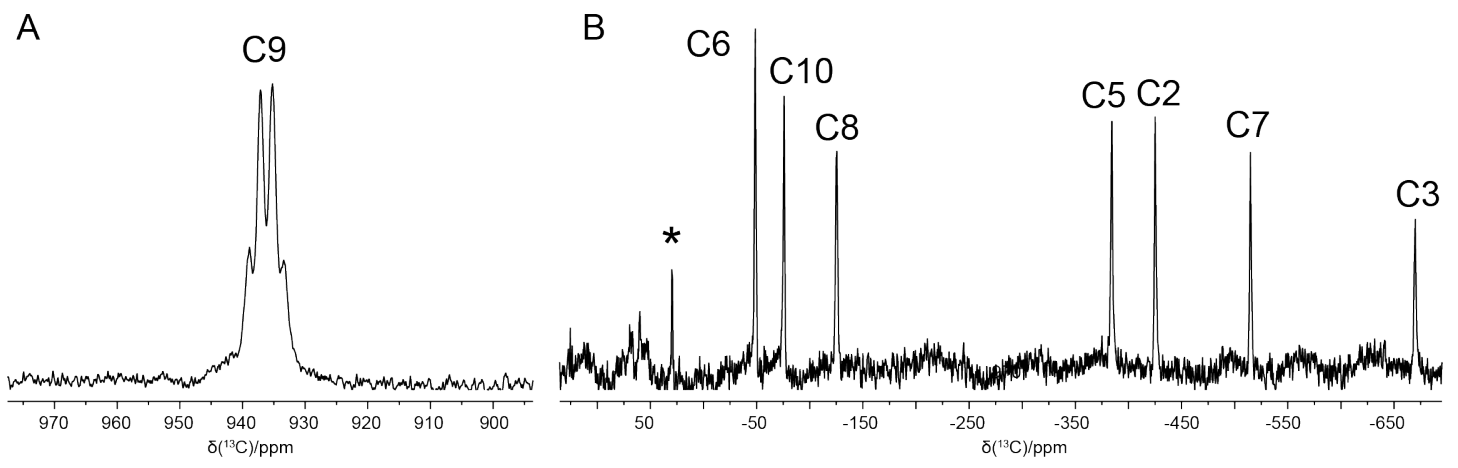

Figure 6. ${ }^{13} \mathrm{C}$ NMR spectra of trans-[Co $\left.{ }^{\mathrm{II}}(\mathbf{t e 2 f 2 p})\right]^{2-}$ complex $\left(151 \mathrm{MHz}, \mathrm{D}_{2} \mathrm{O}, \mathrm{pD} 7.0\right)$. (A) The far-shifted resonance at $936 \mathrm{ppm}$ and (B) the resonances ranging from -700 to $0 \mathrm{ppm}$ were detected separately with pulse offsets of 940 and $-250 \mathrm{ppm}$, respectively. The spectra were acquired with no ${ }^{1} \mathrm{H}$ decoupling; the assignment is based on calculation (see below); the $\mathrm{CH}_{3}$ signal of $t-\mathrm{BuOH}$ is labelled with an asterisk.

The most striking feature in the ${ }^{13} \mathrm{C}$ NMR spectrum of the trans-[Co $\left.{ }^{\mathrm{II}}(\mathbf{t e 2 f 2 p})\right]^{2-}$ anion is the presence of a well-resolved quartet at $936 \mathrm{ppm}\left({ }^{1} J_{\mathrm{CF}}=268 \mathrm{~Hz}\right)$ which is thus clearly assignable 
to the $-\mathrm{CF}_{3}$ group (Figure $6 \mathrm{~A}$ ). ${ }^{*}$ All other ${ }^{13} \mathrm{C}$ NMR signals have negative chemical shifts ranging from -49 to $-670 \mathrm{ppm}$ (Figure 6B). Comparison with the NMR chemical shift of the diamagnetic trans- $\left[\mathrm{Co}{ }^{\mathrm{III}}(\mathbf{t e 2 f 2 p})\right]^{-}\left(122 \mathrm{ppm}\right.$ for $-\mathrm{CF}_{3}$ and $23.6-68.5 \mathrm{ppm}$ for other ${ }^{13} \mathrm{C}$; see the Experimental section) indicates that the huge spread of trans-[Co $\left.{ }^{\mathrm{II}}(\operatorname{te2f} 2 \mathbf{p})\right]^{2-} \mathrm{NMR}$ shifts is caused by the interaction of the ${ }^{13} \mathrm{C}$ nuclei with the paramagnetic cobalt(II). In order to get insight into this interaction and fully assign the ${ }^{13} \mathrm{C}$ spectrum, a combined ab-initio/DFT modelling was performed.

Previous studies have shown that theoretical predictions of pNMR shifts are very sensitive to the geometry of the metal coordination polyhedron. ${ }^{36}$ In the case of the trans-[Co $\left.{ }^{\mathrm{II}}(\mathrm{Hte2f2p})\right]^{-}$ anion, the ligand in the XRD structure contains one single-protonated phosphonate group which breaks the central symmetry of the molecule including the symmetry of the cobalt(II) first coordination sphere. This protonation state is not possible in the aqueous solution at $\mathrm{pH}>7$ used in the NMR experiments, where the phosphonate groups are fully deprotonated. ${ }^{25,40}$ Therefore, after removing the phosphonate hydrogen atom from the XRD structure, the trans$\left[\mathrm{Co}^{\mathrm{II}}(\mathbf{t e 2 f 2 p})\right]^{2-}$ anion was taken as the initial model for the QC calculations and optimised on a DFT level using an implicit dielectric model of the aqueous solution. Although no symmetry restriction was applied during the calculation, the obtained structure is effectively centrosymmetric (see Table 2 for a comparison of crystallographic and DFT-based coordination distances, and Table S3 for the Cartesian coordinates of the calculated structure).

${ }^{*}$ It should be noted that this signal with such an extreme ${ }^{13} \mathrm{C}$ shift was not originally observed. It was looked for and detected with an adjusted pulse offset only after the QC calculations gave an indication that the carbon atom of the $-\mathrm{CF}_{3}$ group is exposed to such a strong paramagnetic shift. 
Table 2. Comparison of coordination distances found in the single-crystal XRD structure of $\left(\mathrm{NH}_{4}\right)\left\{\right.$ trans- $\left.\left[\mathrm{Co}{ }^{\mathrm{II}}(\mathrm{Hte} \mathbf{2 f} \mathbf{p})\right]\right\} \cdot 3.5 \mathrm{H}_{2} \mathrm{O}$ and in the DFT-optimised structure of trans$\left[\mathrm{Co}^{\mathrm{II}}(\mathbf{t e 2 f} \mathbf{2 p})\right]^{2-}$ anion.

\begin{tabular}{lll}
\hline Distance $/ \AA$ & X-ray $^{a}$ & DFT $^{b}$ \\
\hline Co-O11 & $2.071(2) / 2.106(2)$ & 2.042 \\
Co-N1 & $2.253(2) / 2.256(2)$ & 2.281 \\
Co-N4 & $2.147(2) / 2.129(2)$ & 2.148
\end{tabular}

${ }^{a}$ Non-centrosymmetric molecule in the solid state (Figure 2). ${ }^{b}$ Structure optimised on the PBE0-D3BJ level with an implicit model of aqueous solution.

The isotropic NMR shifts were calculated using recent reformulation of Kurland and McGarvey theory established by Vaara. ${ }^{33,34}$ This formalism is generally applicable to any singlemetal centre with known g-tensor ( $\mathbf{g}$ ) and zero-field-splitting (ZFS) tensor (D, for $S \geq 1$ ), and with known hyperfine coupling tensor $\mathbf{A}_{K}$ between the metal ion and the NMR-active nucleus $K$.

The calculated isotropic NMR shift $\left(\delta_{K}^{\text {calc }}\right)$ is obtained according to Equation (1).

$\delta_{K}^{\text {calc }}=\sigma^{\text {ref }}-\sigma_{K}^{\text {orb }}+\delta_{K}^{\text {con }}+\delta_{K}^{\mathrm{pc}}$,

where the terms $\sigma_{\text {ref }}$ and $\sigma_{K}^{\text {orb }}$ are the nuclear shielding of a NMR reference compound and the orbital shielding of a nucleus $K$, respectively. The contact and pseudo-contact shift terms $\delta_{K}^{\text {con }}$ and $\delta_{K}^{\mathrm{pc}}$ correspond to the Fermi contact (FC) and electron-nucleus spin-dipolar (SD) hyperfine interactions, respectively. In this study, experimental chemical shifts of the analogous diamagnetic trans-[Co $\left.{ }^{\mathrm{III}}(\mathbf{t e 2 f 2 p})\right]^{-}$complex $\left(\delta_{K}^{\text {diamag }}\right)$ were used in place of the diamagnetic terms $\left(\sigma^{\text {ref }}-\sigma_{K}^{\text {orb }}\right)$ to calculate the paramagnetic shifts in trans-[CoII $\left.(\mathbf{t e 2 f 2 p})\right]^{2-}$ according to Equation (1). The hyperfine shift terms are obtained by Equations (2) and (3). 
$\delta_{K}^{\text {con }}=\frac{\mu_{B}}{\hbar \gamma_{K} k_{B} T} \frac{1}{3} \operatorname{Tr}[\mathbf{g} \cdot\langle\mathbf{S S}\rangle] A_{K}^{\mathrm{FC}}$

$\delta_{K}^{\mathrm{pc}}=\frac{\mu_{B}}{\hbar \gamma_{K} k_{B} T} \frac{1}{3} \operatorname{Tr}\left[\mathbf{g} \cdot\langle\mathbf{S S}\rangle \cdot \mathbf{A}_{K}^{\mathrm{SD}}\right]$

The $A_{K}^{\mathrm{FC}}$ is the hyperfine coupling constant of the nucleus $K$ and $\mathbf{A}_{K}^{\mathrm{SD}}$ is the second-rank spindipolar term of the total hyperfine coupling tensor $\mathbf{A}_{K}$ of nucleus $K . T$ is the thermodynamic temperature (298 $\mathrm{K}$ in this study), $\hbar, \gamma_{K}, k_{\mathrm{B}}$ and $\mu_{\mathrm{B}}$ are reduced Planck constant, gyromagnetic ratio of the nucleus $K$, Boltzmann constant and Bohr magneton, respectively. "Tr" indicates trace of a matrix. The $\langle\mathbf{S S}\rangle$ is spin dyadic and it can be understood as a generalized $\left\langle\widehat{\boldsymbol{S}}^{2}\right\rangle$ observable in the presence of the zero-field-splitting with contribution from all ZFS levels weighted by their thermal population and including magnetic couplings among them. ${ }^{33}$ It should be mentioned that the pseudo-contact shift of Equation (3), rooted in quantum chemistry, is subject to an ongoing debate since a conflicting expression has been known within the framework of traditional semiempirical theory. ${ }^{34,42}$ Here we just note that, in case of shifts dominated by the contact interaction, the difference between these two frameworks is small.

The g-tensor $\mathbf{g}$, and the ZFS tensor $\mathbf{D}$ used for the calculation of the cobalt(II) spin dyadic (according Ref. 33) were obtained on a correlated multi-reference ab-initio level (see Methods) known to provide reliable results for Co(II) high-spin complexes. ${ }^{36}$ Due to modest computational demands, the method could be applied to the whole complex studied without truncation. An accurate calculation of the ligand hyperfine coupling tensors $\mathbf{A}_{K}$ is currently the main limitation of paramagnetic NMR shift calculation for $3 d$-metal ions. Hybrid DFT methods are currently best suited for calculating hyperfine couplings in systems of a relevant size; however, the amount Hartree-Fock exchange (HFX) admixture in the hybrid DFT functional is not universally transferable between systems ${ }^{43}$ and, due to the absence of a benchmark ab initio computational level for hyperfine coupling, any single hybrid DFT method cannot be fully relied upon. In this 
study, we used for hyperfine coupling calculation the hybrid PBE functional with a HFX admixture ranging from $10 \%$ to $40 \%$ to estimate the uncertainty intervals of paramagnetic NMR shifts in trans-[Co $\left.{ }^{\mathrm{II}}(\mathbf{t e 2 f 2 p})\right]^{2-}$ (Table S4). For the ${ }^{13} \mathrm{C}$ atoms, this interval ranges from $1 \%$ to $8 \%$ of the experimental spectral width. An exception is the extremely shifted atom C9 (for carbon atom numbering, see Scheme 1) where the interval ranges over $500 \mathrm{ppm}$, i.e. $30 \%$ of the experimental spectral width

By comparing the calculated and experimental isotropic ${ }^{13} \mathrm{C}$ NMR shifts in trans$\left[\mathrm{Co}^{\mathrm{II}}(\text { te2f2p) }]^{2-}\right.$ (Figure 7 and Table 3 ), it was possible unambiguously assign the $-\mathrm{CF}_{3}$ carbon atom $C 9\left(\delta^{\exp }=936 \mathrm{ppm}\right)$. This assignment is in agreement with the observed quartet due to the ${ }^{1} J_{\mathrm{CF}}$ coupling. The ethylene C3 carbon atom was assigned unambiguously as well $\left(\delta^{\exp }=-670\right.$ ppm). The signals with experimental chemical shifts $\delta^{\exp }=-425,-515$, and $-384 \mathrm{ppm}$ most probably correspond to ethylene $\mathrm{C} 2$, and propylene $\mathrm{C} 7$ and $\mathrm{C} 5$ carbon atoms of the macrocycle, respectively. The order is not unambiguous. The remaining three resonances, $\delta^{\exp }=-125,-76$, and -49 ppm probably correspond to carbon atoms C8 (fluorine-containing pendant), C10 (phosphonate-containing pendant), and C6 (ring propylene) but the assignment is only tentative. The overall agreement of the calculated NMR shifts with the experimental values is good with the best matching of $\delta_{K}^{\text {calc }}$ obtained with $30 \%$ HFX admixture in the DFT hyperfine coupling calculation.

Table 3. Experimental and predicted ${ }^{13} \mathrm{C}$ and ${ }^{19} \mathrm{~F}$ NMR shifts (in ppm) in trans-[Co(te2f2p) $]^{2-}$ anion, and the calculated Fermi contact hyperfine coupling constants (in MHz; obtained with $30 \%$ HFX admixture in the DFT functional). For the atom numbering scheme, see Scheme 1.

\begin{tabular}{llll}
\hline Nucleus $K$ & $\delta_{K}^{\mathrm{exp}}$ & $\delta_{K}^{\mathrm{calc}}$ & $A_{K}^{\mathrm{FC}}$
\end{tabular}




\begin{tabular}{llll}
\hline $\mathrm{C} 2$ & -425 & -407 & -0.703 \\
$\mathrm{C} 3$ & -670 & -727 & -1.343 \\
$\mathrm{C} 5$ & -384 & -302 & -0.647 \\
$\mathrm{C} 6$ & -49 & 162 & 0.201 \\
$\mathrm{C} 7$ & -515 & -531 & -0.810 \\
$\mathrm{C} 8$ & -125 & -263 & -0.410 \\
$\mathrm{C} 9$ & 936 & 967 & 1.398 \\
$\mathrm{C} 10$ & -76 & -59 & -0.534 \\
\hline $\mathrm{F}$ & -23.0 & $-27^{a}$ & $-0.278^{a}$ \\
\hline
\end{tabular}

${ }^{a}$ Average of the three $-\mathrm{CF}_{3}$ values, assuming isotropic rotation of the group.

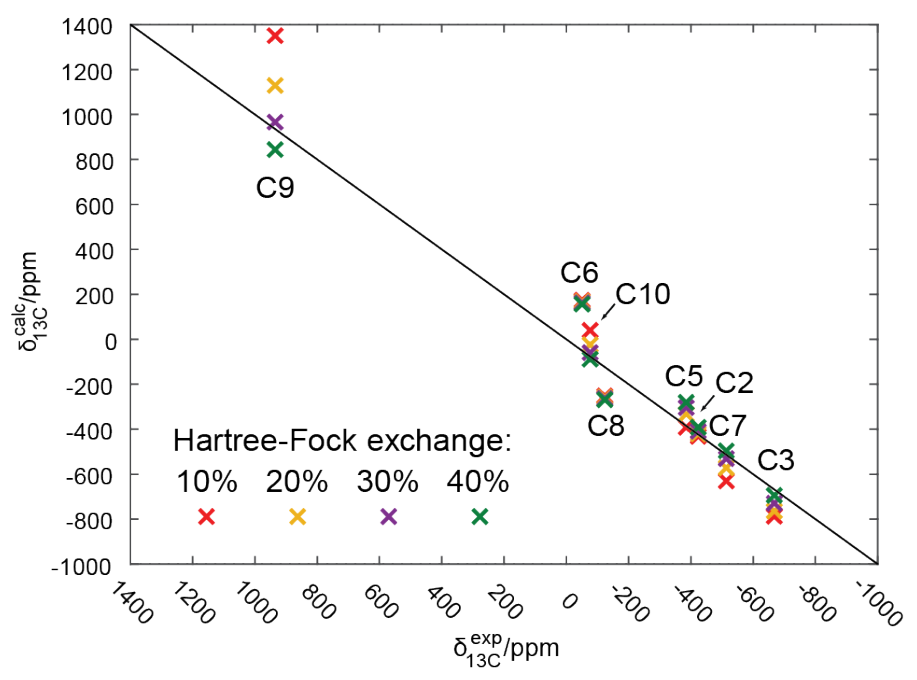

Figure 7. Comparison of experimental (horizontal axis) and calculated (vertical axis) ${ }^{13} \mathrm{C}$ NMR shifts of trans-[Co(te2f2p) $]^{2-}$. The colour of the data-point crosses corresponds to the admixture of Hartree-Fock exchange used in the DFT hyperfine coupling calculations. The solid black line indicates the exact 1:1 calculation-to-experiment correspondence. Root-mean-square deviation is $97.1 \mathrm{ppm}(30 \% \mathrm{HFX})$. For the atom-labelling scheme, see Scheme 1. For the complete set of calculated values, see Table S4. 
The large C9 paramagnetic shift and the possibility to measure the ${ }^{1} J_{\mathrm{CF}}$ coupling in both paramagnetic trans-[Co $\left.{ }^{\mathrm{II}}(\mathbf{t e 2 f} 2 \mathbf{p})\right]^{2-}\left({ }^{1} J_{\mathrm{CF}}=268 \mathrm{~Hz}\right)$ and diamagnetic trans- $\left[\mathrm{Co}^{\mathrm{III}}(\mathbf{t e 2 f} 2 \mathbf{p})\right]^{-}\left({ }^{1} J_{\mathrm{CF}}\right.$ $=282 \mathrm{~Hz}$ ) variants of the complex suggest an intriguing question of whether the ${ }^{1} J_{\mathrm{CF}}$ coupling difference between the paramagnetic and diamagnetic forms, $\Delta_{J}={ }^{1} J_{\mathrm{CF}}^{\mathrm{para}}-{ }^{1} J_{\mathrm{CF}}^{\mathrm{dia}}=-14 \mathrm{~Hz}$, could be ascribed to paramagnetic enhancement. Applying the recent theory of paramagnetically enhanced $J$-coupling, ${ }^{44}$ we found that the ${ }^{1} J_{\mathrm{CF}}$ paramagnetic enhancement is too small, on the order of $-0.25 \mathrm{~Hz}$. The observed ${ }^{1} J_{\mathrm{CF}}$ coupling difference thus has a different cause, likely structural, related to the difference in charge of the central ion.

The NMR shifts were calculated for the ${ }^{1} \mathrm{H}$ and ${ }^{19} \mathrm{~F}$ nuclei of trans- $\left[\mathrm{Co}^{\mathrm{II}}(\mathbf{t e 2 f} \mathbf{2 p})\right]^{2-}$ as well. On the one hand, the broad interval of predicted ${ }^{1} \mathrm{H}$ NMR shifts (see Table S4) in combination with narrower spectral window (270 ppm for ${ }^{1} \mathrm{H}$ compared to $1800 \mathrm{ppm}$ for ${ }^{13} \mathrm{C}$ ), prevent a reliable assignment of the ${ }^{1} \mathrm{H}$ NMR spectrum (Figure S3). On the other hand, the calculated ${ }^{19} \mathrm{~F}$ chemical shift agrees well with its experimental value (Tables 3 and S4). Best agreement was again obtained with $30 \%$ of HFX admixture in the DFT hyperfine coupling calculation.

Individual contributions according to Equation (1) to the calculated NMR shifts in trans$\left[\mathrm{Co}^{\mathrm{II}}(\mathbf{t e 2 f 2 p})\right]^{2-}$ are plotted in Figure 8 and listed in Table S4. Paramagnetic shifts are dominated by the Fermi contact contribution for all ${ }^{13} \mathrm{C}$ nuclei. With the exception of $\mathrm{C} 10$, the pseudocontact shift is negligible. For the ${ }^{19} \mathrm{~F}$ NMR shift, all contributions are significant and the Fermi contact term is the largest, despite a four-bond separation between the cobalt(II) and the fluorine atom. Compared to the very large ${ }^{13} \mathrm{C}$ contact shift of the $-\mathrm{CF}_{3}$ group $(\mathrm{C} 9,871 \mathrm{ppm})$, the rotationally averaged $-\mathrm{CF}_{3}$ fluorine contact shift is surprisingly small (46 ppm). This illustrates 
how indispensable quantum chemistry calculations are for reliable interpretation of paramagnetic NMR spectra.

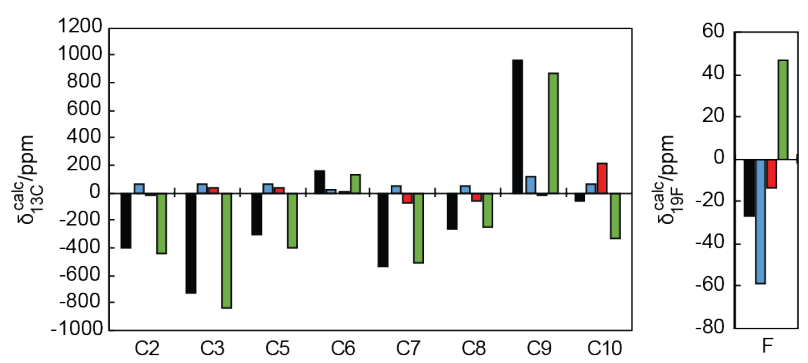

Figure 8. Contributions to calculated ${ }^{13} \mathrm{C}$ and ${ }^{19} \mathrm{~F}$ NMR shifts in trans- $[\mathrm{Co}(\mathbf{t e} 2 \mathbf{f} 2 \mathbf{p})]^{2-}$ anion: The total calculated NMR shift (black), and the diamagnetic (blue), pseudo-contact (red), and Fermi contact (green) contributions. The plotted values were obtained with $30 \%$ of Hartree-Fock exchange admixture in the DFT hyperfine coupling calculation. For the complete set of the calculated values, see Table S4.

The Fermi contact shift is linearly proportional to the contact spin density at the position of the observed nucleus and it directly reflects the spin delocalisation and spin polarisation effects. ${ }^{45,46}$ Therefore, the NMR shifts of trans-[Co(te2f2p) $]^{2-}$ anion can be rationalized by analysis of the unpaired electron density distribution. By far the most of the spin density is localized on the cobalt(II) ion, and only a small fraction is distributed to other atoms (Figure 9) through frontier molecular orbitals with a high contribution of $\mathrm{Co}(\mathrm{II}) 3 d$ shells (Figure 10). Nevertheless, when located at the position of NMR active nuclei, even these small fractions of spin density cause large NMR shifts. 

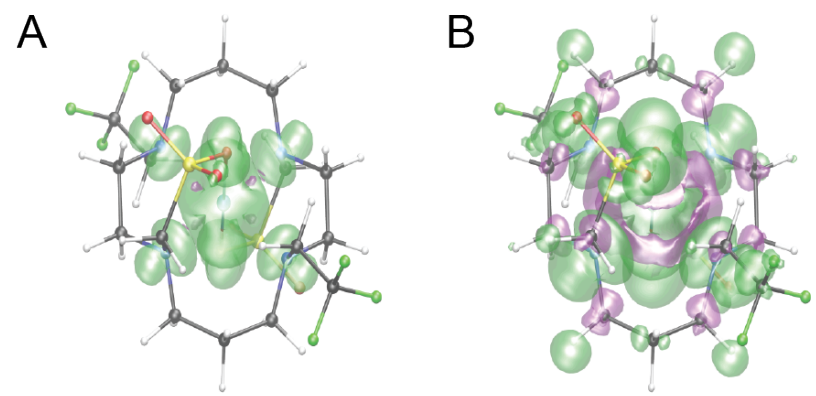

Figure 9: Positive (green) and negative (violet) iso-surfaces of unpaired electron density in the trans-[Co(te2f2p) $]^{2-}$ anion calculated using hybrid PBE functional with $30 \%$ Hartree-Fock exchange admixture. The surfaces correspond to the $(\mathbf{A}) \pm 0.001$ a.u. and $(\mathbf{B}) \pm 0.00015$ a.u. isovalue.
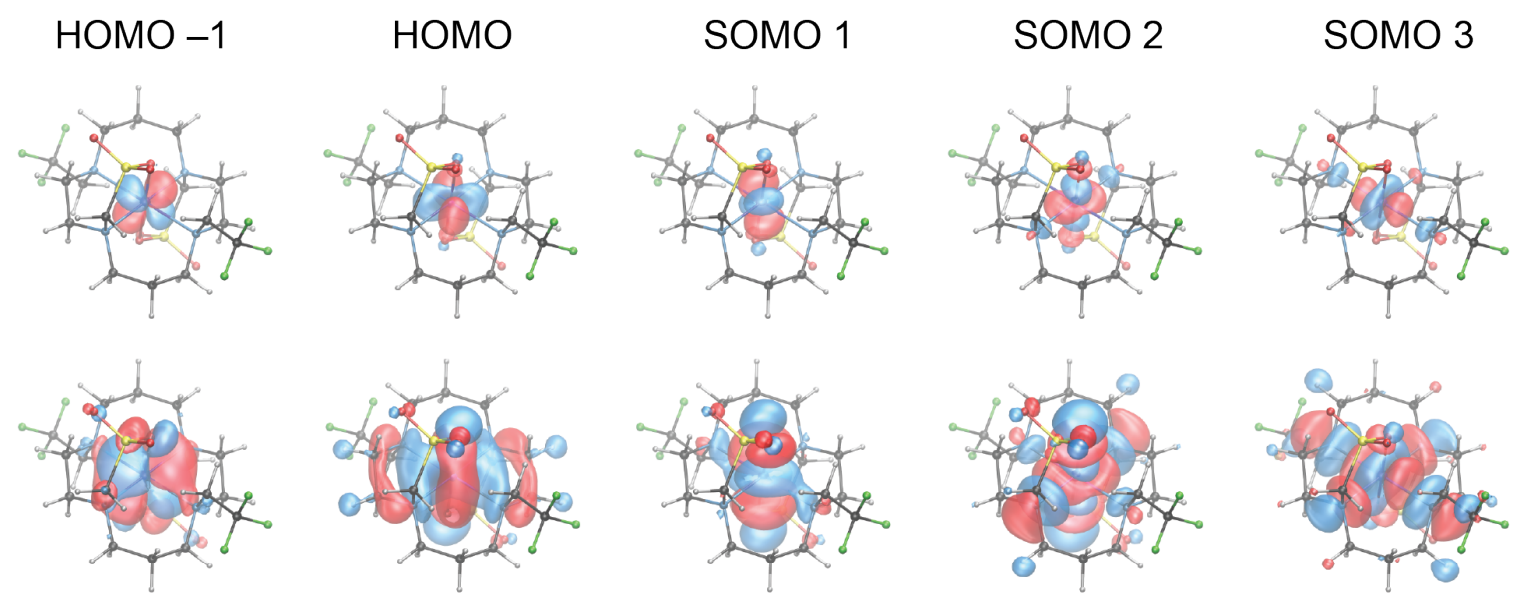

Figure 10 Frontier natural orbitals in trans-[Co(te2f2p) $]^{2-}$ anion corresponding to cobalt(II) $3 d$ orbitals calculated using hybrid PBE functional with 30\% of Hartree-Fock exchange admixture. The surfaces show positive (blue) and negative (red) contours of the frontier orbitals at \pm 0.05 a.u. (upper row) and \pm 0.01 a.u. (lower row) iso-value. 
In the trans-[Co(te2f2p) $]^{2-}$ complex, the frontier orbital centred on $\mathrm{Co}(\mathrm{II})$ consists of two almost degenerated fully-occupied non-bonding orbitals (HOMO -1 and HOMO), one singleoccupied non-bonding orbital (SOMO 1), one singly-occupied N4-Co and O-Co $\sigma-$ anti-bonding orbital (SOMO 2), and one singly-occupied N1-Co $\sigma$-anti-bonding orbital (SOMO 3), see Figure 10. While the SOMO 1 is localized only on the metal centre, the SOMO 2 and SOMO 3 significantly contribute to spin distribution onto the ligand. Through these orbitals, positive spin density is induced on N1 and N4 nitrogen atoms, which induces negative spin density on carbon atoms $\mathrm{C} 2, \mathrm{C} 3, \mathrm{C} 5, \mathrm{C} 7, \mathrm{C} 8$, and $\mathrm{C} 10$ by spin polarization. This explains the negative NMR shift

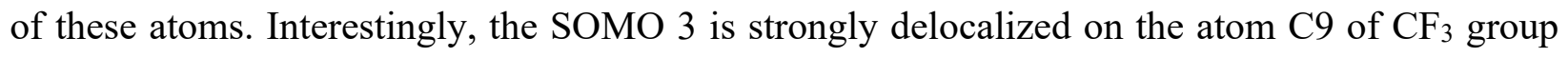
that is consistent with the enormous positive ${ }^{13} \mathrm{C}$ NMR shift of this atom. An expected reason for this efficient delocalisation over three bonds is a combination of the high electronegativity of fluorine atoms and a favourable $\mathrm{Co}-\mathrm{N}-\mathrm{C} 8-\mathrm{C} 9$ dihedral angle (171 ${ }^{\circ}$, Table S3) which enables efficient overlap of the involved atomic orbitals. A comparable dihedral angle dependence of hyperfine couplings, similar to the Karplus curve for vicinal $J$-interaction in NMR spectroscopy, has indeed been reported for several systems, ${ }^{47}$ supporting our present interpretation.

\section{${ }^{19} \mathrm{~F}$ NMR relaxometric properties}

The precise knowledge of three-dimensional and electronic structure of the complexes studied allows us to analyse their nuclear relaxation properties which are of fundamental importance for application in ${ }^{19} \mathrm{~F}$ MRI. Paramagnetic relaxation enhancement and the associated ${ }^{19} \mathrm{~F}$ line broadening is evident from the comparison of ${ }^{19} \mathrm{~F}$ NMR spectra of paramagnetic trans$\left[\mathrm{Co}^{\mathrm{II}}(\mathbf{t e 2 f 2 a})\right]$ and trans-[Co $\left.{ }^{\mathrm{II}}(\mathbf{t e 2} \mathbf{2} \mathbf{p})\right]^{2-}$ with those of their diamagnetic $\mathrm{Co}(\mathrm{III})$ counterparts (Figure 5). While the ${ }^{19} \mathrm{~F}$ NMR linewidth of the diamagnetic Co(III) complexes is approximately 
$3 \mathrm{~Hz}$ (small enough to show the $J$-coupling with protons of the neighbouring methylene group), the $\mathrm{Co}(\mathrm{II})$ ion induces a ten-fold larger linewidth of approx. $30 \mathrm{~Hz}$ at $7.0 \mathrm{~T}$ external field. An even stronger paramagnetic relaxation enhancement was observed for $T_{1}$ relaxation (Table 4). Complexes of cobalt(II) provide approximately 40 -times faster ${ }^{19} \mathrm{~F}$ longitudinal relaxation then the cobalt(III) analogues. This effect is slightly more pronounced for the trans-[Co $\left.{ }^{\mathrm{II}}(\mathbf{t e 2 f} \mathbf{2 p})\right]^{2-}$ complex than for the trans-[Co $\left.{ }^{\mathrm{II}}(\mathbf{t e 2 f} \mathbf{2 a})\right]$ complex.

Table 4. ${ }^{19} \mathrm{~F}$ NMR relaxation times (in ms) and shifts (in ppm) of $\mathrm{Co}^{\mathrm{II} / \mathrm{III}}$ complexes (at $25{ }^{\circ} \mathrm{C}, \mathrm{pH}$ 7) measured at two different static magnetic field strengths $\left(B_{0}\right.$, in T).

\begin{tabular}{|c|c|c|c|c|c|c|}
\hline \multirow{2}{*}{ Complex } & \multicolumn{2}{|c|}{$T_{1}(\mathrm{~ms})$} & \multicolumn{2}{|c|}{$T_{2}^{*}(\mathrm{~ms})$} & \multicolumn{2}{|c|}{$\delta_{\mathrm{F}}(\mathrm{ppm})$} \\
\hline & 7.0 & 9.4 & 7.0 & 9.4 & 7.0 & 9.4 \\
\hline $\operatorname{trans}-\left[\mathrm{Co}^{\mathrm{II}}(\mathbf{t e 2 f} 2 \mathbf{p})\right]^{2-}$ & $12.3(2)$ & $11.94(4)$ & 9.6 & 8.9 & -23.0 & -22.9 \\
\hline trans $-\left[\mathrm{Co}^{\mathrm{II}}(\mathbf{t e 2 f} \mathbf{2 a})\right]$ & $16.1(5)$ & $15.61(5)$ & 11.0 & 10.4 & -25.4 & -25.2 \\
\hline trans $-\left[\mathrm{Co}^{\mathrm{III}}(\mathbf{t e} 2 \mathbf{f} 2 \mathbf{p})\right]^{-}$ & $600(20)$ & $500(19)$ & $360(90)^{a}$ & $321(100)^{a}$ & -59.2 & -59.2 \\
\hline $\operatorname{trans}-\left[\mathrm{Co}^{\mathrm{III}}(\mathbf{t e} 2 \mathbf{f} \mathbf{2 a})\right]^{+}$ & $660(50)$ & $573(31)$ & $540(130)^{a}$ & $460(150)^{a}$ & -59.4 & -59.5 \\
\hline
\end{tabular}

${ }^{a}$ The $T_{2}{ }^{*}$ time is not well defined for $J$-split NMR signals and, therefore, $T_{2}$ times are listed instead.

Within Solomon-Bloembergen-Morgan theory of paramagnetically induced relaxation, the overall NMR relaxation rate of nucleus $K$ can be decomposed into relaxation induced by dipoledipole $\left(R_{1,2 K}^{\mathrm{DD}}\right)$, contact $\left(R_{1,2 K}^{\mathrm{con}}\right)$, and Curie mechanism $\left(R_{1,2 K}^{\mathrm{Cur}}\right) \cdot{ }^{48}$ As the geometry of the complexes is known and hyperfine coupling constants were calculated to predict chemical shifts (see above), correlation times for each relaxation mechanism are the only remaining parameters in the model (see Supporting Information). The rotational correlation time can be estimated from 
the Stokes-Einstein law (Eq. S9) and, therefore, electronic relaxation time $\left(T_{\mathrm{e}}\right)$ of the cobalt(II) ion is the only unknown parameter. It was fitted to minimize the difference between experimental $\left(R_{1,2}^{\exp }\right)$ and predicted $\left(R_{1,2}\right){ }^{19} \mathrm{~F}$ NMR relaxation rates. The obtained electronic relaxation time $T_{\mathrm{e}}$ as well as the nuclear relaxation rates corresponding to different mechanisms are listed in Table 5.

Table 5. Experimental ${ }^{19} \mathrm{~F}$ NMR relax ation rates $\left(R_{1,2}^{\exp }\right)$ and the decomposition of the predicted ${ }^{19} \mathrm{~F}$ NMR relaxation rates $\left(R_{1,2}^{\text {calc }}\right)$ into relaxation induced by dipole-dipole $\left(R_{1,2}^{\mathrm{DD}}\right)$, contact $\left(R_{1,2}^{\mathrm{con}}\right)$, and Curie $\left(R_{1,2}^{\text {Cur }}\right)$ mechanism, based on the fitted electronic relaxation time $\left(T_{\mathrm{e}}\right.$, in ps). The relaxation rates (all in $\mathrm{s}^{-1}$ ) were measured and calculated at two different static magnetic field strengths $\left(B_{0}\right.$, in $\left.\mathrm{T}\right)$.

\begin{tabular}{|c|c|c|c|c|}
\hline \multirow[t]{2}{*}{ Parameter } & \multicolumn{2}{|c|}{ trans $-\left[\mathrm{Co}^{\mathrm{II}}(\mathbf{t e} 2 \mathbf{f} 2 \mathbf{p})\right]^{2-}$} & \multicolumn{2}{|c|}{$\operatorname{trans}-\left[\mathrm{Co}^{\mathrm{II}}(\mathbf{t e 2 f 2 a})\right]$} \\
\hline & 7.0 & 9.4 & 7.0 & 9.4 \\
\hline$R_{1}^{\exp }$ & 81.3 & 83.8 & 62.1 & 64.1 \\
\hline$R_{1}$ & 78.0 & 81.8 & 67.7 & 69.5 \\
\hline$R_{1}^{\mathrm{DD}}$ & 73.3 & 75.3 & 63.1 & 63.6 \\
\hline$R_{1}^{\text {con }}$ & 1.1 & 0.6 & 0.9 & 0.5 \\
\hline$R_{1}^{\mathrm{Cur}}$ & 3.6 & 5.9 & 3.3 & 5.5 \\
\hline$R_{2}^{\exp }$ & 104.0 & 112.0 & 90.9 & 96.2 \\
\hline$R_{2}$ & 106.2 & 113.3 & 86.3 & 90.9 \\
\hline$R_{2}^{\mathrm{DD}}$ & 84.2 & 87.1 & 72.2 & 73.4 \\
\hline$R_{2}^{\text {con }}$ & 17.4 & 18.3 & 10.0 & 10.3 \\
\hline$R_{2}^{\text {Cur }}$ & 4.6 & 7.9 & 4.1 & 7.1 \\
\hline
\end{tabular}




\begin{tabular}{lllll}
\hline$T_{\mathrm{e}}$ & 4.41 & 4.71 & 3.76 & 3.98 \\
\hline
\end{tabular}

The dominant nuclear relaxation mechanism in all cases in Table 5 is the electron-nuclear dipole-dipole relaxation. However for $T_{2}$ nuclear relaxation, the contact mechanism is also important $\left(\approx 16 \% \text { and } \approx 11 \% \text { of the total } R_{2} \text { value for the trans-[Co }{ }^{\mathrm{II}}(\operatorname{te2f} 2 \mathbf{p})\right]^{2-}$ and trans$\left[\mathrm{Co}^{\mathrm{II}}(\mathbf{t e 2 f 2 a})\right]$ complex, respectively). This scalar, through-bond relaxation mechanism is commonly neglected when predicting nuclear relaxation properties of the $f$-metal-based ${ }^{19} \mathrm{~F}$ MRI CAs. ${ }^{49}$ However, for the MRI CAs based on $d$-elements, especially if the observed nucleus is just a couple of bonds away from the metal ion, the contact contribution must be taken into account as it can cause significant decrease of the MRI CA efficiency. Finally, the effect of the Curie relaxation is less important compared to the two other mechanisms. The obtained electronic relaxation times for cobalt(II) are in agreement with literature values and indicate that an Orbach mechanism is probably the dominant electronic relaxation pathway. ${ }^{48}$

The $T_{2} * / T_{1}$ ratio is commonly used to estimate efficiency of paramagnetic molecules as MRI CAs. The ratio reflects the time required to create equilibrium magnetization relative to the time for signal detection. The $T_{2} * / T_{1}$ ratios for trans-[Co(te2f2p) $]^{2-}$ and trans-[Co(te2f2a) $]$ complexes are 0.78 and 0.68 (at $7.0 \mathrm{~T}$ ), respectively. These values are higher (i.e. higher CA efficiency) than those previously published for nickel(II) complexes where $T_{2}{ }^{*} / T_{1}$ ratios ranged from 0.32 to $0.48 .^{25,26}$ They are, however, lower than those reported for a number of other macrocyclic complexes with $f$ and $d$-transition ions, including a Dy(III) complex of a DOTA-diamide derivative with two $-\mathrm{CF}_{3}$ groups $\left(T_{2}{ }^{*} / T_{1}=0.96 ; 4.7 \mathrm{~T}, 295 \mathrm{~K}\right),{ }^{50} \mathrm{Fe}^{\mathrm{II}} / \mathrm{Co} \mathrm{Cl}^{\mathrm{II}} / \mathrm{Ni}^{\mathrm{II}}$ complexes of a DOTA-tetramide derivative with six $-\mathrm{CF}_{3}$ groups $\left(T_{2}{ }^{*} / T_{1} \sim 0.9 ; 9.4 \mathrm{~T}, 296 \mathrm{~K}\right),{ }^{22}$ or a $\mathrm{Ni}(\mathrm{II})$ complex of cross-bridged cyclam derivatives with one/two $-\mathrm{CF}_{3}$ groups $\left(T_{2}{ }^{*} / T_{1} \sim 0.8 ; 7.1 \mathrm{~T}, 298\right.$ K). ${ }^{28}$ Nevertheless, the $T_{2}{ }^{*} / T_{1}$ ratios of the present cobalt(II) complexes are significantly higher 
than those in M-DOTA-AmF 12 complexes with the $T_{2}{ }^{*} / T_{1}$ values $0.07-0.18$ and $0.57(7 \mathrm{~T}, 298$ $\mathrm{K})$ for $\mathrm{M}=\mathrm{Ln}^{3+}$ and $\mathrm{Fe}^{2+}$, respectively. ${ }^{51}$ They are also higher or comparable with the $T_{2}{ }^{*} / T_{1}$ values $0.12-0.87(7 \mathrm{~T}, 298 \mathrm{~K})$ of $\mathrm{Ln}(\mathrm{III})$ complexes of DOTA-mono/diamide derivatives with two $-\mathrm{CF}_{3}$ groups. ${ }^{52}$ Both cobalt(II) complexes studied also show a significantly better $T_{2}{ }^{*} / T_{1}$ ratio than e.g. micelles of perfluorinated molecules with dissolved paramagnetic complexes, 0.31 and $0.05(9.4 \mathrm{~T}, 298 \mathrm{~K})$ for $\mathrm{Fe}^{\mathrm{III}}$ and $\mathrm{Gd}^{\mathrm{III}}$ acetylacetonate complexes, respectively, ${ }^{53}$ or $0.47(9.4 \mathrm{~T}$, $298 \mathrm{~K}$ ) for a Fe $\mathrm{Fe}^{\mathrm{III}}$ Schiff base complex. ${ }^{54}$

\section{Conclusion}

We prepared and investigated kinetically inert high-spin cobalt(II) complexes of carboxylate/phosphonate cyclam derivatives together with their cobalt(III) analogues as diamagnetic references. These complexes are examples of a growing family of paramagnetic MRI probes based on transition metal ions, and the present study demonstrates that these systems exhibit a convenient $T_{2}{ }^{*} / T_{1}$ ratio which, under suitable acquisition conditions, can lead to efficient ${ }^{19} \mathrm{~F}$ MRI CA. In addition, paramagnetic chemical shifts of the trans-[Co $\left.{ }^{\mathrm{II}}(\mathrm{te} 2 \mathrm{f} 2 \mathrm{p})\right]^{2-}$ complex were interpreted with the help of ab-initio and DFT calculations. The simulations indicate delocalisation of single-occupied molecular orbitals from cobalt(II) ion to ligand atoms, especially to the relatively distant $-\mathrm{CF}_{3}$ group. The resulting contact spin density explains an extreme ${ }^{13} \mathrm{C}$ NMR shift of almost $1000 \mathrm{ppm}$. The simulation also shows the importance of contact contribution to the ${ }^{19} \mathrm{~F} T_{2}$ nuclear relaxation which, unlike in lanthanide(III) ion complexes, cannot be neglected in transition metal ion complexes. These calculations are among only a handful available for transition metal-based systems with macrocyclic ligands. Thus, this study may help future works with interpretation of paramagnetic NMR shifts and relaxation data 
of novel transition-metal MRI CAs as the area is much less developed than the analogous field of trivalent lanthanide complexes.

\section{Experimental}

Commercial chemicals (Merck-Aldrich, CheMatech, Lachema) were used as obtained. The ligands, $\mathrm{H}_{2}$ te2f $2 \mathbf{a}$ and $\mathrm{H}_{4}$ te2f2p, were available from our previous work. ${ }^{25,26}$ The $\left[\mathrm{Co}\left(\mathrm{NH}_{3}\right)_{6}\right] \mathrm{Cl}_{2}$ complex was prepared by the published procedure ${ }^{55}$ and stored in flame-sealed Ar-flushed ampoule (as a solid) or dissolved in $\approx 10 \%$ oxygen-free aq. $\mathrm{NH}_{3}$ (to get a stock solution for the title complex syntheses). The NMR spectra were recorded employing VNMRS300, VarianUNITY INOVA 400, Bruker Avance III 400, and Bruker Avance III 600 spectrometers using 5-mm sample tubes. NMR chemical shifts are given in ppm and coupling constants are reported in Hz. Unless stated otherwise, all NMR spectra were collected at $25{ }^{\circ} \mathrm{C}$. For the ${ }^{1} \mathrm{H}$ and ${ }^{13} \mathrm{C}$ NMR measurements in $\mathrm{D}_{2} \mathrm{O}, t$ - $\mathrm{BuOH}$ was used as internal standard $\left(\delta\left({ }^{1} \mathrm{H}\right)=1.25 \mathrm{ppm}\right.$, $\left.\delta\left({ }^{13} \mathrm{C}\right)=30.29 \mathrm{ppm}\right)$. $\mathrm{pD}$ values were calculated adding +0.4 as a correction to $\mathrm{pH}$ reading using a combined glass electrode calibrated with commercial buffer solutions in $\mathrm{H}_{2} \mathrm{O}$. For ${ }^{19} \mathrm{~F}$ NMR measurements, 2,2,2-trifluoroethanol $\left(\mathrm{TFE}, \delta\left({ }^{19} \mathrm{~F}\right)=-77.0 \mathrm{ppm}\right)$ was used as internal standard. Abbreviations s (singlet), $\mathrm{t}$ (triplet), $\mathrm{q}$ (quartet), $\mathrm{m}$ (multiplet) and b (broad) are used in order to express the signal multiplicities/shape. Symbol $\alpha$ and $\beta$ indicate resolved but not assigned (axial vs. equatorial) geminal protons of $\mathrm{CH}_{2}$ groups. Longitudinal relaxation times $T_{1}$ were measured using an inversion recovery sequence. Transversal relaxation times were measured using a CPMG pulse sequence. Relaxation times $T_{2}{ }^{*}$ were calculated from signal half-width $v_{1 / 2}$ using the relation $T_{2}^{*}=1 /\left(\pi v_{1 / 2}\right)$. The concentration of the complexes for spectral measurements was $\sim 10$ mg per $0.5 \mathrm{~mL}$ of solvent. In case of trans-[Co $\left.{ }^{\mathrm{II}}(\mathbf{t e 2 f 2 a})\right]$, a saturated solution of the complex in 
water was used. ESI-MS spectra in positive or negative mode were acquired on the Bruker ESQUIRE 3000 spectrometer with ion-trap detection. High-resolution mass spectra were recorded on Orbitrap XL (Thermo Fisher Scientific).

\section{$\left(\mathrm{NH}_{4}\right)\left\{\right.$ trans- $\left.\left[\mathrm{Co}{ }^{\mathrm{II}}(\mathrm{Hte2f2p})\right]\right\}$}

Under argon, $\mathrm{H}_{4}$ te2f2p $(200 \mathrm{mg}, 360 \mu \mathrm{mol})$, was dissolved in oxygen-free aq. $\mathrm{NH}_{3}(5 \%, 20$ $\mathrm{mL})$ and $\left[\mathrm{Co}\left(\mathrm{NH}_{3}\right)_{6}\right] \mathrm{Cl}_{2}$ stock solution in $\approx 10 \%$ oxygen-free aq. $\mathrm{NH}_{3}(86 \mathrm{~mm}, 10 \mathrm{~mL}$, i.e. 860 $\mu$ mol, 2.4 equiv.) was added. The reaction proceeded under reflux and under a flow of oxygenfree ammonia overnight. Presence of the free ligand was tested using ${ }^{19} \mathrm{~F}$ NMR. On air, the reaction mixture was evaporated to dryness and the crude product was purified by column chromatography $\left(\mathrm{SiO}_{2}, 6 \times 3 \mathrm{~cm}\right)$ with $\mathrm{EtOH} /$ conc. aq. $\mathrm{NH}_{3}=5: 1$ as a mobile phase. Fractions containing pure product were combined (visually detectable by a pink colour), solvents were evaporated to dryness and the solid residue was recrystallized from a minimal amount of water with a drop of $5 \%$ aq. $\mathrm{NH}_{3}$ by vapor diffusion of acetone. Yield $174 \mathrm{mg}(79 \%)$. For ${ }^{1} \mathrm{H},{ }^{19} \mathrm{~F}$ and ${ }^{13} \mathrm{C}$ NMR, see Figures 4, 5 and 6, respectively. HR-MS(-): 608.0803; calc. for $\left\{[\mathrm{Co}(\mathbf{t e 2 f 2 p})]^{2-}+\right.$ $\left.\mathrm{H}^{+}\right\}^{-}:$608.0804. TLC $\left(\mathrm{SiO}_{2} ; \mathrm{EtOH} /\right.$ conc. aq. $\left.\mathrm{NH}_{3}=1 / 5\right): R_{\mathrm{F}} 0.6 .{ }^{1} \mathrm{H}\left(300 \mathrm{MHz}, \mathrm{D}_{2} \mathrm{O}, \mathrm{pD} 10.9\right)$ : 182 (bs); 173 (bs); 115 (bs); 82 (bs); 71 (bs); 39 (bs); 34 (bs); 33 (bs); 18 (bs); -1 (bs); -80 (bs); -82 (bs); -104 (bs); ${ }^{13} \mathrm{C}\left(151 \mathrm{MHz}, \mathrm{D}_{2} \mathrm{O}, \mathrm{pD}\right.$ 7): 936 (q, $\left.{ }^{1} J_{\mathrm{CF}}=268 \mathrm{~Hz}, \mathrm{C} 9\right) ;-49(\mathrm{~s}, \mathrm{C} 6) ;-76$ (s, C10); -125 (s, C8); -384 (s, C5); -425 (s, C2); -515 (s, C7); -670 (s, C3). ${ }^{19} \mathrm{~F}\left(282 \mathrm{MHz}, \mathrm{D}_{2} \mathrm{O}\right.$, $\mathrm{pH} \sim 7):-23.0$;

The effective magnetic moment $\left(\mu_{\mathrm{B}}=4.9(2) \mu_{\mathrm{B}}\right)$ was measured using Evans method for detection of the bulk magnetic susceptibility through a difference in chemical shift of $t$-BuOH between the sample at a given concentration and a reference solution in a coaxial insert tube. ${ }^{56}$ 
Solution of trans-[Co $\left.{ }^{\mathrm{III}}(\mathbf{t e} \mathbf{2 f} \mathbf{2 p})\right]^{-}$

Complex $\left(\mathrm{NH}_{4}\right)\left[\mathrm{Co}{ }^{\mathrm{II}}(\mathrm{Hte2f2p})\right](8 \mathrm{mg}, 13 \mu \mathrm{mol})$ was dissolved in $\mathrm{D}_{2} \mathrm{O}(0.7 \mathrm{~mL}, \mathrm{pD} 10.9)$ containing conc. aq. $\mathrm{NH}_{3}(10 \mu \mathrm{L})$. The oxidant, solid $m$-chloroperoxybenzoic acid (MCPBA, assayed as $70-75 \%, 13 \mathrm{mg}, \approx 53 \mu \mathrm{mol}, \approx 4$ equiv.) was added. The reaction was left to proceed for 10 min and excess of the benzoic acid derivatives was filtered off. The NMR experiments were performed directly with this sample. NMR data: ${ }^{1} \mathrm{H}\left(600 \mathrm{MHz}, \mathrm{D}_{2} \mathrm{O}, \mathrm{pD}\right.$ 6.9): $1.52(\mathrm{~d}$, $\left.{ }^{2} J_{\mathrm{HH}}=14 \mathrm{~Hz}, 2 \mathrm{H}, \mathrm{H} 7 \alpha\right) ; 2.15\left(\mathrm{~d},{ }^{2} J_{\mathrm{HH}}=17 \mathrm{~Hz}, 2 \mathrm{H}, \mathrm{H} 6 \alpha\right) ; 2.33\left(\mathrm{~d},{ }^{2} J_{\mathrm{HH}}=12 \mathrm{~Hz}, 2 \mathrm{H}, \mathrm{H} 5 \beta\right) ; 2.43$ $\left(\mathrm{d},{ }^{2} J_{\mathrm{HH}}=16 \mathrm{~Hz}, 2 \mathrm{H}, \mathrm{H} 6 \beta\right) ; 2.44\left(\mathrm{~d},{ }^{2} J_{\mathrm{HH}}=16 \mathrm{~Hz}, 2 \mathrm{H}, \mathrm{H} 10 \alpha\right) ; 2.95\left(\mathrm{~d},{ }^{2} J_{\mathrm{HH}}=14 \mathrm{~Hz}, 2 \mathrm{H}, \mathrm{H} 3 \beta\right) ;$ $3.08(\mathrm{bm}, 2 \mathrm{H}, \mathrm{H} 8 \alpha) ; 3.14\left(\mathrm{t},{ }^{2} J_{\mathrm{HH}}={ }^{3} J_{\mathrm{HH}}=14 \mathrm{~Hz}, 2 \mathrm{H}, \mathrm{H} 7 \beta\right) ; 3.35\left(\mathrm{dq},{ }^{2} J_{\mathrm{HH}}=18.7 \mathrm{~Hz},{ }^{3} J_{\mathrm{HF}}=9.4\right.$ $\mathrm{Hz}, 2 \mathrm{H}, \mathrm{H} 8 \beta) ; 3.66\left(\mathrm{t},{ }^{2} J_{\mathrm{HH}}=15 \mathrm{~Hz}, 2 \mathrm{H}, \mathrm{H} 10 \beta\right) ; 3.72\left(\mathrm{t},{ }^{2} J_{\mathrm{HH}}={ }^{3} J_{\mathrm{HH}}=13 \mathrm{~Hz}, 2 \mathrm{H}, \mathrm{H} 5 \alpha\right) ; 3.86(\mathrm{t}$, $\left.{ }^{2} J_{\mathrm{HH}}={ }^{3} J_{\mathrm{HH}}=14 \mathrm{~Hz}, 2 \mathrm{H}, \mathrm{H} 3 \alpha\right) ; 4.36\left(\mathrm{t},{ }^{2} J_{\mathrm{HH}}={ }^{3} J_{\mathrm{HH}}=14 \mathrm{~Hz}, 2 \mathrm{H}, \mathrm{H} 2 \alpha\right) ;{ }^{13} \mathrm{C}\left\{{ }^{1} \mathrm{H}\right\}\left(151 \mathrm{MHz}, \mathrm{D}_{2} \mathrm{O}\right.$, pD 6.9): $23.6(\mathrm{~s}, \mathrm{C} 6) ; 52.2\left(\mathrm{q},{ }^{2} J_{\mathrm{CF}}=29 \mathrm{~Hz}, \mathrm{C} 8\right) ; 52.7(\mathrm{~s}, \mathrm{C} 7) ; 56.3(\mathrm{~s}, \mathrm{C} 2) ; 57.1\left(\mathrm{~d},{ }^{1} J_{\mathrm{PC}}=131 \mathrm{~Hz}\right.$, $\mathrm{C} 10) ; 60.7\left(\mathrm{~d},{ }^{3} J_{\mathrm{PC}}=9.4 \mathrm{~Hz}, \mathrm{C} 5\right) ; 68.5(\mathrm{~s}, \mathrm{C} 3) ; 122\left(\mathrm{q},{ }^{1} J_{\mathrm{CF}}=285 \mathrm{~Hz}, \mathrm{C} 9\right) ;{ }^{19} \mathrm{~F}\left(282 \mathrm{MHz}, \mathrm{D}_{2} \mathrm{O}\right.$, pD 6.9): $-59.22\left(\mathrm{t},{ }^{3} \mathrm{~J}_{\mathrm{HF}}=9.4 \mathrm{~Hz}\right) ;{ }^{31} \mathrm{P}\left(121 \mathrm{MHz}, \mathrm{D}_{2} \mathrm{O}, \mathrm{pD}\right.$ 6.9): 38.25 .

\section{trans-[Co $\left.{ }^{\mathrm{II}}(\mathbf{t e 2 f 2 a})\right]$}

Under argon, $\mathrm{H}_{2}$ te2f2a $(100 \mathrm{mg}, 420 \mu \mathrm{mol})$ was dissolved in oxygen-free solution of $\left[\mathrm{Co}\left(\mathrm{NH}_{3}\right)_{6}\right] \mathrm{Cl}_{2}(60 \mathrm{mM})$ in $\approx 10 \%$ aq. $\mathrm{NH}_{3}(10 \mathrm{~mL}$, i.e. $600 \mu \mathrm{mol}, 1.4$ equiv. $)$. The reaction mixture was refluxed under gentle flow of oxygen-free ammonia. The resulting trans$\left[\mathrm{Co}^{\mathrm{II}}(\mathbf{t e 2 f 2 a})\right]$ precipitated from the reaction mixture in a form of small crystals during the reaction course. The solid product was filtered off after disappearance of the free ligand signal in ${ }^{19} \mathrm{~F}$ NMR of reaction solution ( 14 h). Yield $60 \mathrm{mg}(60 \%)$. The complex is hardly soluble in 
water allowing characterization only by ${ }^{1} \mathrm{H}$ and ${ }^{19} \mathrm{~F}$ NMR (Figures 5 and 6 , respectively). HRMS(+): 538.1417 (calc. for $\left\{[\operatorname{Co}(\mathbf{t e 2 f 2 a})]+\mathrm{H}^{+}\right\}^{+}$538.1420), 560.1235 (calc. for $\{[\mathrm{Co}(\operatorname{te2f2a})]+$ $\left.\mathrm{Na}^{+}\right\}^{+}$560.1239). ${ }^{1} \mathrm{H}\left(300 \mathrm{MHz}, \mathrm{D}_{2} \mathrm{O}, \mathrm{pD}\right.$ 9.1): 246 (bs); 204 (bs); 151 (bs); 86 (bs); 96 (bs) 70 (bs); 60 (bs); 58 (bs); 55 (bs); -33 (bs); -64 (bs); -88 (bs); -92 (bs); -129 (bs); ${ }^{19} \mathrm{~F}$ (282 MHz, $\left.\mathrm{D}_{2} \mathrm{O}, \mathrm{pH} \sim 7\right):-25.4$.

\section{Solution of trans-[CoII $(\mathbf{t e 2 f 2 a})]^{+}$}

The complex trans-[CoII $(\mathbf{t e 2 f 2 a})](10 \mathrm{mg}, 19 \mu \mathrm{mol})$ was suspended in $\mathrm{D}_{2} \mathrm{O}(0.7 \mathrm{~mL}, \mathrm{pD} 9.2)$ containing conc. aq. $\mathrm{NH}_{3}(10 \mu \mathrm{L})$. The oxidant, solid $m$-chloroperoxybenzoic acid (MCPBA, assayed as $70-75 \%, 18 \mathrm{mg}, \approx 78 \mu \mathrm{mol}, \approx 4$ equiv.) was added. The reaction was left to proceed for $10 \mathrm{~min}$ and excess of benzoic acid derivatives was filtered off. Prepared cobalt(III) complex was studied only in solution without isolation. NMR data: ${ }^{1} \mathrm{H}\left(600 \mathrm{MHz}, \mathrm{D}_{2} \mathrm{O}, \mathrm{pD}\right.$ 6.9): 2.16 (dt, $\left.{ }^{2} J_{\mathrm{HH}}=14.3,{ }^{3} J_{\mathrm{HH}}=2.8 \mathrm{~Hz}, 2 \mathrm{H}, \mathrm{H} 7 \alpha\right) ; 2.29\left(\mathrm{dt},{ }^{2} J_{\mathrm{HH}}=17.3,{ }^{3} J_{\mathrm{HH}}=2.3 \mathrm{~Hz}, 2 \mathrm{H}, \mathrm{H} 6 \alpha\right) ; 2.50(\mathrm{~m}$, $2 \mathrm{H}, \mathrm{H} 6 \beta) ; 2.54(\mathrm{~m}, 2 \mathrm{H}, \mathrm{H} 2 \alpha) ; 2.65\left(\mathrm{t},{ }^{2} J_{\mathrm{HH}}=13.6 \mathrm{~Hz}, 2 \mathrm{H}, \mathrm{H} 7 \beta\right) ; 2.81\left(\mathrm{dq},{ }^{2} J_{\mathrm{HH}}=17.6 \mathrm{~Hz},{ }^{3} J_{\mathrm{HF}}=\right.$ $8.3 \mathrm{~Hz}, 2 \mathrm{H}, \mathrm{H} 8 \beta) ; 2.83+2.86(\mathrm{~m}, 4 \mathrm{H}, \mathrm{H} 2 \beta+\mathrm{H} 5 \beta) ; 3.24\left(\mathrm{~d},{ }^{2} J_{\mathrm{HH}}=14.1 \mathrm{~Hz}, 2 \mathrm{H}, \mathrm{H} 3 \alpha\right) ; 3.39$ (dq, $\left.{ }^{2} J_{\mathrm{HH}}=17.6,{ }^{3} J_{\mathrm{HF}}=9.1 \mathrm{~Hz}, 2 \mathrm{H}, \mathrm{H} 8 \alpha\right) ; 3.57\left(\mathrm{~d},{ }^{2} J_{\mathrm{HH}}=19.2 \mathrm{~Hz}, 2 \mathrm{H}, \mathrm{H} 10 \beta\right) ; 3.60\left(\mathrm{td},{ }^{2} J_{\mathrm{HH}}=13.4\right.$, $\left.J_{\mathrm{HH}}{ }^{2}=3.1 \mathrm{~Hz}, 2 \mathrm{H}, \mathrm{H} 5 \alpha\right) ; 4.00(\mathrm{~m}, 2 \mathrm{H}, \mathrm{H} 3 \beta$ overlapped with TFE$) ; 4.59\left(\mathrm{~d},{ }^{2} J_{\mathrm{HH}}=19.2 \mathrm{~Hz}, 4 \mathrm{H}\right.$, $\mathrm{H} 10 \alpha) ;{ }^{13} \mathrm{C}\left\{{ }^{1} \mathrm{H}\right\}\left(151 \mathrm{MHz}, \mathrm{D}_{2} \mathrm{O}, \mathrm{pD} 6.9\right): 23.0$ (s, C6); 49.53 (q, $\left.{ }^{2} J_{\mathrm{CF}}=30.5 \mathrm{~Hz}, \mathrm{C} 8\right) ; 54.7$ (s, C7); 56.6 (s, C2); 58.0 (s, C5); 61.8 (s, C10); 66.0 (s, C3); 121.68 (q, $\left.{ }^{1} J_{\mathrm{CF}}=280.0 \mathrm{~Hz}, \mathrm{C} 9\right) ; 183.6$ (s, C11); ${ }^{19} \mathrm{~F}\left(282 \mathrm{MHz}, \mathrm{D}_{2} \mathrm{O}, \mathrm{pD} 6.9\right):-59.47\left(\mathrm{t},{ }^{3} \mathrm{~J}_{\mathrm{HF}}=8.5 \mathrm{~Hz}\right)$.

\section{X-ray diffraction study}


Single crystals of trans-[Co $\left.{ }^{\mathrm{II}}(\mathbf{t e 2 f 2 a})\right] \cdot 2 \mathrm{MeOH}$ were grown by cooling of saturated hot solution of trans-[Co $\left.{ }^{\mathrm{II}}(\mathbf{t e 2 f 2 a})\right]$ in methanol. Single crystals of $\left(\mathrm{NH}_{4}\right)\left\{\right.$ trans $\left.-\left[\mathrm{Co}{ }^{\mathrm{II}}(\mathrm{Hte2f2p})\right]\right\} \cdot 3.5 \mathrm{H}_{2} \mathrm{O}$ and $\left(\mathrm{NH}_{4}\right)\left\{\right.$ trans-[Co $\left.\left.{ }^{\mathrm{III}}(\mathbf{t e 2 f} \mathbf{2} \mathbf{p})\right]\right\} \cdot 11 \mathrm{H}_{2} \mathrm{O}$ were prepared by vapor diffusion of acetone into solution of the corresponding complex in water with a small amount of ammonia. Other details on refinement of X-ray data and final experimental data (Table S2) are given in Supporting Information. Complete crystallographic records for the three structures have been deposited in the Cambridge Crystallographic Data Centre under CCDC reference numbers 18611641861166.

\section{Calculation details on the trans- $\left[\mathrm{Co}^{I I}(\operatorname{te} 2 \mathrm{f} 2 \mathrm{p})\right]^{2-}$ complex}

Geometry optimisation was performed in Gaussian 09 (Revision D.01) ${ }^{57}$ by DFT employing the hybrid PBE0 functional ${ }^{58,59}$ with Grimme's D3 dispersion correction using Becke-Johnson damping. ${ }^{60,61}$ The triple-zeta basis set TZVP was used for all atoms. ${ }^{62}$ An UltraFine integration grid was applied. Bulk solvent effects of water were simulated by polarisable continuum model. ${ }^{63}$ The identity of energetic minima was verified by vibrational frequency analysis.

The $g$-tensor and the zero-field-splitting tensor of the cobalt(II) complex were obtained in Orca $4.0^{64}$ by the effective Hamiltonian approach applied on the wave function calculated in-vacuo using the state-averaged complete active space self-consistent field method (with seven electrons in five $3 d$-orbitals, i.e. SA-CASSCF(7,5), weighing equally all 10 quartet and 40 doublet roots) with the $n$-electron valence state perturbation theory (NEVPT2) correction. The TZVP base set was used for all the atoms. ${ }^{62}$ The hyperfine coupling tensors for all NMR active nuclei were calculated in Orca $4.0^{64}$ with a series of hybrid PBE functionals with Hartree-Fock exchange varying from 10 to $40 \%$. The IGLO-III basis set ${ }^{65}$ was used for the NMR active atoms and 
Def2-TZVPD for the rest. ${ }^{66,67}$ Paramagnetic NMR shifts were calculated with the methodology of Vaara et al. ${ }^{33}$ The temperature $300 \mathrm{~K}$ was used in all calculations of NMR shifts. The calculated NMR shifts of symmetry-equivalent nuclei were averaged, same as were the ${ }^{19} \mathrm{~F}$ chemical shifts of the freely rotating $-\mathrm{CF}_{3}$ group.

\section{Analysis of relaxation times}

Electronic relaxation time of $\mathrm{Co}(\mathrm{II})$ was calculated by minimizing the difference between experimental $T_{1}\left({ }^{19} \mathrm{~F}\right)$ and $T_{2}\left({ }^{19} \mathrm{~F}\right)$ relaxation times [assumed equal to $T_{2} *\left({ }^{19} \mathrm{~F}\right)$ ] and the values predicted from Solomon-Bloembergen-Morgan equations, see SI and Ref. 48. The diamagnetic contribution to the nuclear relaxation rate was neglected. Average metal-fluorine distances were taken from X-ray structures and hyperfine coupling constants $\left(A_{K}^{\mathrm{FC}}\right)(0.227 \mathrm{MHz}$ and $0.278 \mathrm{MHz}$ for trans-[Co $\left.{ }^{\mathrm{II}}(\mathbf{t e 2 f 2 a})\right]$ and trans-[Co $\left.{ }^{\mathrm{II}}(\mathbf{t e 2 f 2 p})\right]^{2-}$, respectively) from the DFT calculation using $30 \%$ Hartee-Fock exchange admixture (see above). Rotation correlation times $(0.19 \mathrm{~ns}$ and $0.21 \mathrm{~ns}$ for trans-[Co $\left.{ }^{\mathrm{II}}(\mathbf{t e 2 f} \mathbf{2 a})\right]$ and trans-[Co $\left.{ }^{\mathrm{II}}(\mathbf{t e 2 f} 2 \mathbf{p})\right]^{2-}$, respectively) were estimated from Stokes law in water solution (Eq. S9).

\section{ASSOCIATED CONTENT}

Supporting Information contains: data on complexation mechanism and decomplexation kinetics; X-ray experimental data and details; Cartesian coordinates of the DFT-optimised trans$\left[\mathrm{Co}^{\mathrm{II}}(\mathbf{t e 2 f 2 p})\right]^{2-}$ structure; detailed results of the pNMR shift calculations; comparison of calculated ${ }^{1} \mathrm{H}$ NMR shifts with experimental ${ }^{1} \mathrm{H}$ NMR spectrum of trans-[Co $\left.{ }^{\mathrm{II}}(\mathbf{t e 2 f 2 p})\right]^{2-}$ and theory for ${ }^{19} \mathrm{~F}$ NMR relaxation calculations.

Accession Codes: CCDC 1861164-1861166 contain the supplementary crystallographic data for this paper. These data can be obtained free of charge via 
www.ccdc.cam.ac.uk/data_request/cif, or by emailing data_request@ccdc.cam.ac.uk, or by contacting The Cambridge Crystallographic Data Centre, 12 Union Road, Cambridge CB2 1EZ, UK; fax: +44 1223336033 .

\section{AUTHOR INFORMATION}

\section{Corresponding Author}

*petrh@natur.cuni.cz, blahutj89@gmail.com, Hlavova 2030, 12843 Prague 2, Czech Republic.

\section{Author Contributions}

The manuscript was written through contributions of all authors. All authors have given approval to the final version of the manuscript.

\section{Funding Sources}

The Ministry of Education of the Czech Republic (Grant LTC 17067).

The ELIXIR-CZ project (LM2015047), part of the international ELIXIR infrastructure.

The IT4Innovations National Supercomputing Center (LM2015070).

\section{ACKNOWLEDGMENT}

This study was funded by the Ministry of Education of the Czech Republic (Grant LTC 17067). Computational resources were provided by the project e-Infrastruktura CZ (LM2018140) and IT4Innovations National Supercomputing Center (LM2015070). The authors thank Dr. I. Císařová for X-ray data acquisition. The work was performed in the framework of the EU COST CA15209 Action.

\section{REFERENCES}


${ }^{1}$ The Chemistry of Contrast Agents in Medical Magnetic Resonance Imaging, $2^{\text {nd }}$ Ed.; Merbach, A.; Helm, L.; Tóth, É.; Eds.; Wiley: Chichester 2013.

${ }^{2}$ Contrast Agents for MRI: Experimental Methods; Pierre V. C; M. J. Allen, Eds. RSC, London 2018.

${ }^{3}$ Wahsner J.; Gale, E. M.; Rodríguez-Rodríguez A.; Caravan, P. Chemistry of MRI contrast agents: Current challenges and new frontiers. Chem. Rev. 2019, 119, 957-1057.

${ }^{4}$ Hermann, P.; Kotek, J.; Kubíček, V.; Lukeš, I. Gadolinium(III) complexes as MRI contrast agents: ligand design and properties of the complexes. Dalton Trans. 2008, 3027-3047.

${ }^{5}$ (a) Lux, J.; Sherry, A. D. Advances in gadolinium-based MRI contrast agent designs for monitoring biological processes in vivo. Curr. Opinion Chem. Biol. 2018, 45,121-130. (b) Pierre, V. C.; Harris, S. M.; Pailloux, S. L. Comparing strategies in the design of responsive contrast agents for magnetic resonance imaging: A case study with copper and zinc. Acc. Chem. Res. 2018, 51, 342-351.

${ }^{6}$ (a) Shuvaev, S.; Starck, M.; Parker, D. Responsive, water-soluble europium(III) luminescent probes. Chem. Eur. J. 2017, 23, 9974-9989. (b) Aulsebrook, M. L.; Graham, B.; Grace, M. R.; Tuck, K. L. Lanthanide complexes for luminescence-based sensing of low molecular weight analytes. Coord. Chem. Rev. 2018, 375, 191-220. (c) Mathieu, E.; Sipos, A.; Demeyere, E.; Phipps, D.; Sakaveli, D.; Borbas, K. E. Lanthanide-based tools for the investigation of cellular environments. Chem. Commun. 2018, 54, 10021-10035.

${ }^{7}$ Nitsche, C.; Otting, G. Pseudocontact shifts in biomolecular NMR using paramagnetic metal tags. Prog. Nucl. Magn. Reson. Spectrosc. 2017, 98-99, 20-49. 
${ }^{8}$ (a) Pandya, D.; Bhatt, N.; Yuan, H.; Day, C.; Ehrmann, B.; Wright, M.; Bierbach, U.; Wadas, T. Zirconium tetraazamacrocycle complexes display extraordinary stability and provide a new strategy for zirconium-89-based radiopharmaceutical development. Chem. Sci., 2016, 8, 23042314. (b) Price, T. W.; Greenman, J.; Stasiuk, G. J. Current advances in ligand design for inorganic positron emission tomography tracers ${ }^{68} \mathrm{Ga},{ }^{64} \mathrm{Cu},{ }^{89} \mathrm{Zr}$ and ${ }^{44} \mathrm{Sc}$. Dalton Trans. 2016, 45, 15702-15724. (c) Price, E. W.; Orvig, C. Matching chelators to radiometals for radiopharmaceuticals. Chem. Soc. Rev. 2014, 43, 260-290. (d) Burke, B. P.; Seemann, J.; Archibald, S. J.; Advanced chelator design for metal complexes in imaging applications: radiopharmaceuticals, protein targeting, and conjugation. Adv. Inorg. Chem., 2016, 68, 301-339. (e) Paterson, B. M.; Donnelly P. S. Macrocyclic bifunctional chelators and conjugation strategies for copper-64 radiopharmaceuticals. Adv. Inorg. Chem., 2016, 68, 223-251.

${ }^{9}$ (a) Drahoš, B.; Lukeš, I.; Tóth, É. Manganese(II) complexes as potential contrast agents for MRI. Eur. J. Inorg. Chem. 2012, 1975-1986. (b) Garda, Z.; Molnár, E.; Kálmán, F. K.; Botár, R.; Nagy, V.; Baranyai, Z.; Brücher, E.; Kovács, Z.; Tóth, I.; Tircsó. G. Effect of the nature of donor atoms on the thermodynamic, kinetic and relaxation properties of $\mathrm{Mn}(\mathrm{II})$ complexes formed with some trisubstituted 12-membered macrocyclic ligands. Front. Chem. 2018, 6, 232.

10 (a) Wang, J.; Gondrand, C.; Toutia, F.; Hasserodt J. A pair of highly biotolerated diamagnetic and paramagnetic iron(II) complexes displaying electroneutrality. Dalton Trans. 2015, 44, 15391-15395. (b) Gondrand, C.; Touti, F.; Godart, E.; Berezhanskyy, Y.; Jeanneau, E.; Maurin, P.; Hasserodt, J. Spring-loaded iron(II) complexes as magnetogenic probes reporting on a chemical analyte in water. Eur. J. Inorg. Chem. 2015, 1376-1382. (c) H. Wang, V. C. Jordan, I. A. Ramsay, M. Sojoodi, B. C. Fuchs, K. K. Tanabe, P. Caravan, Eric M. Gale, Molecular magnetic resonance imaging using a redox-active iron complex. J. Am. Chem. Soc. 2019, 141, 
5916-5925. (d) E. M. Snyder, D. Asik, S. M. Abozeid, A. Burgio, G. Bateman, S. G. Turowski, J. A. Spernyak, J. R. Morrow, A class of $\mathrm{Fe}^{\mathrm{III}}$ macrocyclic complexes with alcohol donor groups as effective $T_{1}$ MRI contrast agents. Angew. Chem. Int. Ed. 2020, 59, 2414-2419.

11 (a) Soesbe, T. C.; Wu, Y.; Sherry, A. D. Advantages of paramagnetic CEST complexes having slow-to-intermediate water exchange properties as responsive MRI agents. NMR Biomed. 2013, 26, 829-838. (b) Tóth, É.; Bonnet, C. S. Responsive ParaCEST Contrast Agents. Inorganics. 2019, 7, 68.

12 Schmidt, R.; Nippe, N.; Strobel, K.; Masthoff, M.; Reifschneider, O.; Castelli, D. D.; Höltke, C.; Aime, S.; Karst, U.; Sunderkötter, C.; Bremer, C. Faber C. Highly shifted proton MR imaging: Cell tracking by using direct detection of paramagnetic compounds. Radiology 2014, 272, 785-795.

${ }^{13}$ (a) Harvey, P.; Blamire, A. M.; Wilson, J. I.; Finney, K.-L. N. A.; Funk, A. M.; Senanayake, P. K.; Parker, D. Moving the goal posts: enhancing the sensitivity of PARASHIFT proton magnetic resonance imaging and spectroscopy. Chem. Sci. 2013, 4, 4251-4258. (b) Senanayake, P. K.; Rogers, N. J.; Finney, K.-L. N. A.; Harvey, P.; Funk, A. M.; Wilson, J. I.; O’Hogain, D.; Maxwell, R.; Parker, D.; Blamire, A. M. A new paramagnetically shifted imaging probe for MRI. Magn. Reson. Med. 2017, 77, 1307-1317. (c) Mason, K.; Rogers, N. J.; Suturina, E. A.; Kuprov, I.; Aguilar, J. A.; Batsanov, A. S.; Yufit, D. S.; Parker D. PARASHIFT probes: solution NMR and X-ray structural studies of macrocyclic ytterbium and yttrium complexes. Inorg. Chem. 2017, 56, 4028-4038.

${ }^{14}$ Harnden, A. C.; Parker, D.; Rogers, N. J. Employing paramagnetic shift for responsive MRI probes. Coord. Chem. Rev. 2019, 383, 30-42. 
15 Tirotta, I.; Dichiarante, V.; Pigliacelli, C.; Cavallo, G.; Terraneo, G.; Bombelli, F. B. ${ }^{19}$ F Magnetic resonance imaging (MRI): From design of materials to clinical applications. Chem. Rev. 2015, 115, 1106-1129.

16 Fluorine Magnetic Resonance Imaging; Flogel, U., Ahrens, E., Eds.; CRC Press: Boca Raton, FL, 2016.

${ }^{17}$ Peterson, K. L.; Srivastava, K.; Pierre, V. C. Fluorinated paramagnetic complexes: Sensitive and responsive probes for magnetic resonance spectroscopy and imaging. Front. Chem. 2018, 6 , 160.

${ }^{18}$ Xie, D.; Yu, M.; Kadakia, R. T.; Que, E. L. ${ }^{19}$ F magnetic resonance activity-based sensing using paramagnetic Metals. Acc. Chem. Res. 2020, 53, 2-10

${ }^{19}$ (a) Olatunde, A. O.; Bond, C. J.; Dorazio, S. J.; Cox, J. M.; Benedict, J. B.; Daddario, M. D.; Spernyak, J. A.; Morrow. J. R. Six, seven or eight coordinate $\mathrm{Fe}^{\mathrm{II}}, \mathrm{Co}^{\mathrm{II}}$ or $\mathrm{Ni}^{\mathrm{II}}$ complexes of amide-appended tetraazamacrocycles for paraCEST thermometry. Chem. Eur. J. 2015, 21, 182918300. (b) Abozeid, S. M.; Snyder, E. M.; Lopez, A. P.; Steuerwald, C. M.; Sylvester, E.; Ibrahim, K. M.; Zaky, R. R.; Abou-El-Nadar, H. M.; Morrow. J. R. Nickel(II) complexes as paramagnetic shift and paraCEST agents. Eur. J. Inorg. Chem. 2018, 1902-1908. (c) Abozeid, S. M.; Snyder, E. M.; Tittiris, T. Y.; Steuerwald, C. M.; Nazarenko, A. Y.; Morrow J. R. Innersphere and outer-sphere water interactions in Co(II) paraCEST agents. Inorg. Chem. 2018, 57, 2085-2095. (d) Bond, C. J.; Sokolow, G. E.; Crawley, M. R.; Burns, P. J.; Cox, J. M.; Mayilmurugan, R.; Morrow, J. R. Exploring inner-sphere water interactions of Fe(II) and Co(II) complexes of 12-membered macrocycles to develop CEST MRI probes. Inorg. Chem. 2019, 58, 8710-8719. 
${ }^{20}$ Srivastava, K.; Ferrauto, G.; Young, V. G., Jr.; Aime, S.; Pierre V. C. Eight-Coordinate, stable $\mathrm{Fe}(\mathrm{II})$ complex as a dual ${ }^{19} \mathrm{~F}$ and CEST contrast agent for ratiometric $\mathrm{pH}$ imaging. Inorg. Chem. 2017, 56, 12206-12213.

${ }^{21}$ a) Thorarinsdottir, A. E.; Harris, T. D. Dramatic enhancement in pH sensitivity and signal intensity through ligand modification of a dicobalt PARACEST probe. Chem. Commun. 2019, 55, 794-797. b) Du, K.; Thorarinsdottir, A. E.; Harris, T. D. Selective binding and quantitation of calcium with a cobalt-based magnetic resonance probe. J. Am. Chem. Soc. 2019, 141, $7163-7172$.

${ }^{22}$ Yu, M.; Bouley, B. S.; Xie, D.; Que, E. L. Highly fluorinated metal complexes as dual ${ }^{19} \mathrm{~F}$ and PARACEST imaging agents. Dalton Trans. 2019, 48, 9337-9341.

23 Pradhan, R. N.; Chakraborty, S.; Bharti, P.; Kumar, J.; Ghosh, A.; Singh, A. K. Seven coordinate $\mathrm{Co}(\mathrm{II})$ and six coordinate $\mathrm{Ni}(\mathrm{II})$ complexes of an aromatic macrocyclic triamide ligand as paraCEST agents for MRI. Dalton Trans. 2019, 48, 8899-8910

24 (a) Tsitovich, P. B.; Gendron, F.; Nazarenko, A. Y.; Livesay, B. N.; Lopez, A. P.; Shores, M. P.; Autschbach, J.; Morrow. J. R. Low-spin Fe(III) macrocyclic complexes of imidazoleappended 1,4,7-Triazacyclononane as paramagnetic probes. Inorg. Chem. 2018, 57, 8364-8374. (b) Tsitovich, P. B.; Tittiris, T. Y.; Cox, J. M.; Benedict, J. B.; Morrow. J. R. Fe(II) and Co(II) Nmethylated cyclen complexes as paraSHIFT agents with large temperature dependent shifts. Dalton Trans., 2018, 47, 916-924. (c) Tsitovich, P. B.; Cox, J. M.; Benedict, J. B.; Morrow. J. R. Six-coordinate iron(II) and cobalt(II) paraSHIFT agents for measuring temperature by magnetic resonance spectroscopy. Inorg. Chem. 2016, 55, 700-716. 
25 Blahut, J.; Hermann, P.; Gálisová, A.; Herynek, V.; Císařová, I.; Tošner, Z.; Kotek, J. Nickel(II) complexes of $\mathrm{N}-\mathrm{CH}_{2} \mathrm{CF}_{3}$ cyclam derivatives as contrast agents for ${ }^{19} \mathrm{~F}$ magnetic resonance imaging. Dalton Trans. 2016, 45, 474-478.

26 Blahut, J. ; Bernášek, K.; Gálisová, A.; Herynek, V.; Císařová, I.; Kotek, J.; Lang, J.; Matějková, S.; Hermann P. Paramagnetic ${ }^{19} \mathrm{~F}$ relaxation enhancement in nickel(II) complexes of $N$-trifluoroethyl cyclam derivatives and cell labeling for ${ }^{19} \mathrm{~F}$ MRI. Inorg. Chem. 2017, 56, $13337-13348$.

27 (a) Gaudette, A. I.; Thorarinsdottir, A. E.; Harris T. D. pH-Dependent spin state population and ${ }^{19} \mathrm{~F}$ NMR chemical shift via remote ligand protonation in an iron(II) complex. Chem. Commun., 2017, 53, 12962-12965. (b) Thorarinsdottir, A. E.; Gaudette, A. I.; Harris T. D. Spincrossover and high-spin iron(II) complexes as chemical shift ${ }^{19} \mathrm{~F}$ magnetic resonance thermometers. Chem. Sci., 2017, 8, 2448-2456.

28 Pujales-Paradela, R.; Savić, T.; Brandariz, I.; Pérez-Lourido, P.; Angelovski, G.; EstebanGómez, D.; Platas-Iglesias C. Reinforced Ni(II)-cyclam derivatives as dual ${ }^{1} \mathrm{H} /{ }^{19} \mathrm{~F}$ MRI probes. Chem. Commun. 2019, 55, 4115-4118.

${ }^{29}$ a) Yu, M.; Bouley, B. S.; Xie, D.; Enriquez, J. S.; Que E. L. ${ }^{19}$ F PARASHIFT probes for magnetic resonance detection of $\mathrm{H}_{2} \mathrm{O}_{2}$ and peroxidase activity. J. Am. Chem. Soc. 2018, 140, 10546-10552. b) Yu, M.; Xie, D.; Phan, K. P.; Enriquez, J. S.; Luci, J. L.; Que, E. L. A Co ${ }^{\mathrm{II}}$ complex for ${ }^{19} \mathrm{~F}$ MRI-based detection of reactive oxygen species. Chem. Commun. 2016, 52, 13885-13888. c) Xie, D.; Ohman, L. E.; Que, E. L. Towards Ni(II) complexes with spin switches for ${ }^{19} \mathrm{~F}$ MR-based pH sensing. Magn. Reson. Mater. Phys. Chem. Med. 2019, 32, 89-96. 
${ }^{30}$ Bertini, I.; Luchinat, C.; Parigi G.; Ravera, E. NMR of Paramagnetic Molecules, $2^{\text {nd }}$ Edn; Elsevier: Amsterdam, 2017.

31 Pell, A. J.; Pintacuda, G.; Grey, C. P. Paramagnetic NMR in solution and the solid state. Prog. Nucl. Magn. Reson. Spectrosc. 2019, 111, 1-271.

${ }^{32}$ Heuvel, W. V. d.; Soncini, A. NMR chemical shift in an electronic state with arbitrary degeneracy. Phys. Rev. Lett., 2012, 109, 073001.

${ }^{33}$ Vaara, J.; Rouf, S. A.; Mareš, J. Magnetic couplings in the chemical shift of paramagnetic NMR. J. Chem. Theory Comput., 2015, 11, 4840-4849.

${ }^{34}$ Kurland, R. J.; McGarvey, B. R. Isotropic NMR shifts in transition metal complexes: The calculation of the Fermi contact and pseudocontact terms. J. Magn. Reson. 1970, 2, 286-301.

${ }^{35}$ Rouf, S. A.; Mareš, J.; Vaara, J. ${ }^{1} \mathrm{H}$ chemical shifts in paramagnetic Co(II) pyrazolylborate complexes: A first-principles study. J. Chem. Theory Comput. 2015, 11, 1683-1691.

36 Benda, L.; Mareš, J.; Ravera, E.; Parigi, G.; Luchinat, C.; Kaupp, M.; Vaara, J. Pseudocontact NMR shifts over the paramagnetic metalloprotein CoMMP-12 from first principles. Angew. Chem. Int. Ed., 2016, 55, 14713-14717.

${ }^{37}$ Dorazio, S. J.; Olatunde, A. O.; Spernyak, J. A.; Morrow, J. R. CoCEST: cobalt(II) amideappended paraCEST MRI contrast agents. Chem. Commun., 2013, 49, 10025-10027.

38 Drabowicz, J.; Jordan, F.; Kudzin, M. H.; Kudzin, Z. H.; Stevens, C. V.; Urbaniak, P.; Reactivity of aminophosphonic acids. Oxidative dephosphonylation of 1-aminoalkylphosphonic acids by aqueous halogens. Dalton Trans., 2016, 45, 2308-2317. 
${ }^{39}$ Bosnich, B.; Poon, C. K.; Tobe, M. L. Complexes of cobalt (III) with a cyclic tetradentate secondary amine. Inorg. Chem. 1965, 4, 1102-1108.

${ }^{40}$ (a) Kotek, J.; Vojtí̌̌ek, P.; Císařová, I.; Hermann, P.; Lukeš, I. Unusual cis/trans isomerism in octahedral nickel(II) complexes with 1,4,8,11-tetraazacyclotetradecane-1,8bis(methylphosphonic acid) as a ligand. Collect. Czech. Chem. Commun. 2001, 66, 363-381. (b) Kotek, J.; Lubal, P.; Hermann, P.; Císařová, I.; Lukeš, I.; Godula, T.; Svobodová, I.; Táborský, P.; Havel, J. Unusually high thermodynamic stability and extraordinary kinetic inertness of copper(II) complexes with 1,4,8,11-tetraazacyclotetradecane-1,8-bis(methylphosphonic acid). Example of a rare isomerism between kinetically inert penta- and hexacoordinated copper(II) complexes. Chem. Eur. J. 2003, 9, 233-248. (c) Füzerová, S.; Kotek, J.; Císařová, I.; Hermann, P.; Binnemans, K.; Lukeš. I. Cyclam (1,4,8,11-tetraazacyclotetradecane) with one methylphosphonate pendant arm: a new ligand for selective copper(II) binding. Dalton Trans. 2005, 2908-2915. (d) Svobodová, I.; Lubal, P.; Plutnar, J.; Kotek, J.; Havlíčková, J.; Hermann, P.; Lukeš I. Thermodynamic, kinetic and the solid-state studies of divalent metal complexes of 1,4,8,11-tetraazacyclotetradecane (cyclam) bearing two trans (1,8-) methylphosphonic acid pendant arms. Dalton Trans. 2006, 5184-5197. (e) Havlíčková, J.; Medová, H.; Vitha, T.; Kotek, J.; Císařová, I.; Hermann, P. Coordination properties of cyclam $(1,4,8,11-$ tetraazacyclotetradecane) endowed with two methylphosphonic acid pendant arms in the 1,4positions. Dalton Trans. 2008, 5378-5386.

${ }^{41}$ A. F. Holleman, E. Wiberg, Inorganic Chemistry, Academic Press, Berlin 2001, pp. 483.

${ }^{42}$ (a) Parigi, G.; Benda, L.; Ravera, E.; Romanelli, M.; Luchinat, C. Pseudocontact shifts and paramagnetic susceptibility in semiempirical and quantum chemistry theories. J. Chem. Phys. 
2019, 150, 144101. (b) Cerofolini, L.; Silva, J. M.; Ravera, E.; Romanelli, M.; Geraldes, C. F. G. C.; Macedo, A. L.; Fragai, M.; Parigi, G.; Luchinat, C. How do nuclei couple to the magnetic moment of a paramagnetic center? A new theory at the gauntlet of the experiments. J. Phys. Chem. Lett. 2019, 10, 3610-3614.

${ }^{43}$ Munzarová, M.; Kaupp, M. A critical validation of density functional and coupled-cluster approaches for the calculation of EPR hyperfine coupling constants in transition metal complexes J. Phys. Chem. A, 1999, 103, 9966-9983; Munzarová, M. L.; Kubáček, P.; Kaupp, M. Mechanisms of EPR hyperfine coupling in transition metal complexes J. Am. Chem. Soc., 2000, 122, 11900-11913; Mondal, A.; Kaupp, M. Quantum-chemical approach to NMR chemical shifts in paramagnetic solids applied to $\mathrm{LiFePO}_{4}$ and $\mathrm{LiCoPO}_{4}$. J. Phys. Chem. Lett., 2018, 9, $1480-1484$.

${ }^{44}$ Cherry, P. J.; Rouf, S. A.; Vaara, J. Paramagnetic enhancement of nuclear spin-spin coupling J. Chem. Theory Comput. 2017, 13, 1275-1283.

${ }^{45}$ I. Bertini, C. Luchinat, G. Parigi, E. Ravera, NMR of Paramagnetic Molecules, $2^{\text {nd }}$ Edn., Chap. 2: The hyperfine shift. Elsevier, Amsterdam 2017.

${ }^{46}$ Autschbach, J. in Annual Reports in Computational Chemistry, Vol. 11, D. A. Dixon, Ed., Elsevier, Amsterdam 2015, pp. 3-36.

${ }^{47}$ a) Szalontai, G.; Csonka, R.; Speier, G.; Kaizer, J.; Sabolović, J. Solid-state NMR study of paramagnetic bis(alaninato- $\left.\kappa^{2} N, O\right) \operatorname{copper}(\mathrm{II}) \quad$ and $\quad$ bis(1-amino(cyclo)alkane-1-carboxylato$\left.\kappa^{2} N, O\right)$ copper(II) complexes: Reflection of stereoisomerism and molecular mobility in ${ }^{13} \mathrm{C}$ and ${ }^{2} \mathrm{H}$ fast magic angle spinning spectra. Inorg. Chem., 2015, 54, 4663-4677. b) Bertini, I.; Capozzi, F.; Luchinat, C.; Piccioli M.; Vila, A. J. The iron-sulfur cluster (Fe4S4) centers in ferredoxins 
studied through proton and carbon hyperfine coupling. Sequence-specific assignments of cysteines in ferredoxins from Clostridium acidi urici and Clostridium pasteurianum. J. Am. Chem. Soc., 1994, 116, 651-660. c) Bertini, I.; Luchinat, C.; Parigi G.; Walker, F. A. Heme methyl ${ }^{1} \mathrm{H}$ chemical shifts as structural parameters in some low- spin ferriheme proteins. J. Biol. Inorg. Chem., 1999, 4, 515-519.

${ }^{48}$ Bertini, I.; Luchinat, C.; Parigi, G.; Ravera, E. NMR of Paramagnetic Molecules, $2^{\text {nd }}$ Edn., Chapter 4: Relaxation. Elsevier, Amsterdam 2017.

${ }^{49}$ Chalmers, K. H.; De Luca, E.; Hogg, N. H. M.; Kenwright, A. M.; Kuprov, I.; Parker, D.; Botta, M.; Wilson, J. I.; Blamire, A. M. Design principles and theory of paramagnetic fluorinelabelled lanthanide complexes as probes for ${ }^{19} \mathrm{~F}$ magnetic resonance: a proof-of-concept study. Chem. Eur. J., 2010, 16, 134-148.

${ }^{50}$ Chalmers, K. H.; Botta M.; Parker, D. Strategies to enhance signal intensity with paramagnetic fluorine-labelled lanthanide complexes as probes for ${ }^{19} \mathrm{~F}$ magnetic resonance. Dalton Trans., 2011, 40, 904-13.

${ }^{51}$ Srivastava, K.; Weitz, E. A.; Peterson, K. L.; Marjańska, M.; Pierre, V. C. Fe- and LnDOTAm-F12 are effective paramagnetic fluorine contrast agents for MRI in water and blood. Inorg. Chem., 2017, 56, 1546-1557.

52 (a) Pujales-Paradela, R.; Savić, T.; Pérez-Lourido, P.; Esteban-Gómez, D.; Angelovski, G.; Botta, M.; Platas-Iglesias, C. Lanthanide complexes with ${ }^{1} \mathrm{H}$ paraCEST and ${ }^{19} \mathrm{~F}$ response for magnetic resonance imaging applications. Inorg. Chem. 2019, 58, 7571-7583. (b) PujalesParadela, R.; Savic, T.; Esteban-Gómez, D.; Angelovski, G.; Carniato, F.; Botta, M.; PlatasIglesias, C. Gadolinium(III)-based dual ${ }^{1} \mathrm{H} /{ }^{19} \mathrm{~F}$ MRI probes. Chem.-Eur. J. 2019, 25, 4782-4792. 
53 Kislukhin, A. A.; Xu, H.; Adams, S. R.; Narsinh, K. H.; Tsien, R. Y.; Ahrens, E. T. Paramagnetic fluorinated nanoemulsions for sensitive cellular fluorine-19 magnetic resonance imaging. Nature Mater., 2016, 15, 662-668.

54 Jahromi, A. H.; Wang, C.; Adams, S. R.; Zhu, W.; Narsinh, K.; Xu, H.; Gray, D. L.; Tsien, R. Y.; Ahrens, E. T. Fluorous-soluble metal chelate for sensitive fluorine-19 magnetic resonance imaging nanoemulsion probes. ACS Nano 2019, 13, 143-151.

55 Kauffman, G. B.; Sugisaka, N.; Emerson, K.; Bares, L. A.; Houk, C. C. Hexaamminecobalt(II) chloride. Inorg. Synth., 1967, 9, 157-160.

56 Corsi, D. M.; Platas-Iglesias, C.; van Bekkum, H.; Peters, J. A. Determination of paramagnetic lanthanide(III) concentrations from bulk magnetic susceptibility shifts in NMR spectra. Magn. Reson. Chem., 2001, 39, 723-726.

${ }^{57}$ Gaussian 09, Revision D.01, Gaussian, Inc., Wallingford, CT, 2016.

${ }^{58}$ Perdew, J. P.; Burke, K.; Ernzerhof, M. Generalized gradient approximation made simple. Phys. Rev. Lett., 1996, 77, 3865-3868.

${ }^{59}$ Perdew, J. P.; Ernzerhof, M.; Burke, K. Rationale for mixing exact exchange with density functional approximations. J. Chem. Phys., 1996, 105, 9982-9985.

60 Grimme, S.; Antony, J.; Ehrlich, S.; Krieg, H. A consistent and accurate ab initio parameterization of density functional dispersion correction (DFT-D) for the 94 elements $\mathrm{H}-\mathrm{Pu}$, J. Chem. Phys. 2010, 132, 154104.

${ }^{61}$ Grimme, S.; Ehrlich, S.; Goerigk, L. Effect of the damping function in dispersion corrected density functional theory. J. Comput. Chem. 2011, 32, 1456-1465. 
${ }^{62}$ Schaefer, A.; Huber, C.; Ahlrichs, R. Fully optimized contracted Gaussian-basis sets of triple zeta valence quality for atoms Li to Kr. J. Chem. Phys. 1994, 100, 5829-35.

${ }^{63}$ Scalmani, G.; Frisch, M. J. Continuous surface charge polarizable continuum models of solvation. I. General formalism. J. Chem. Phys. 2010, 132, 114110.

${ }^{64}$ Neese, F. The ORCA program system. Wiley Interdiscipl. Rev. Comput. Mol. Sci., 2012, 2, $73-78$.

${ }^{65}$ Kutzelnigg, W.; Fleischer, U.; Schindler, M. NMR - Basic Principles and Progress, Vol. 23, Springer, Heidelberg, 1990.

${ }^{66}$ Weigend, F.; Ahlrichs, R. Balanced basis sets of split valence, triple zeta valence and quadruple zeta valence quality for $\mathrm{H}$ to Rn: Design and assessment of accuracy. Phys. Chem. Chem. Phys., 2005, 7, 3297-3305.

${ }^{67}$ Rappoport, D.; Furche, F. Property-optimized Gaussian basis sets for molecular response calculations. J. Chem. Phys., 2010, 133, 134105. 


\section{SYNOPSIS}

Paramagnetically induced NMR shifts and relaxations of cobalt(II) complexes with trifluoroethyl cyclam derivatives were interpreted on the basis of electron spin density calculations, and the complexes are suggested as ${ }^{19} \mathrm{~F}$ MRI contrast agents.

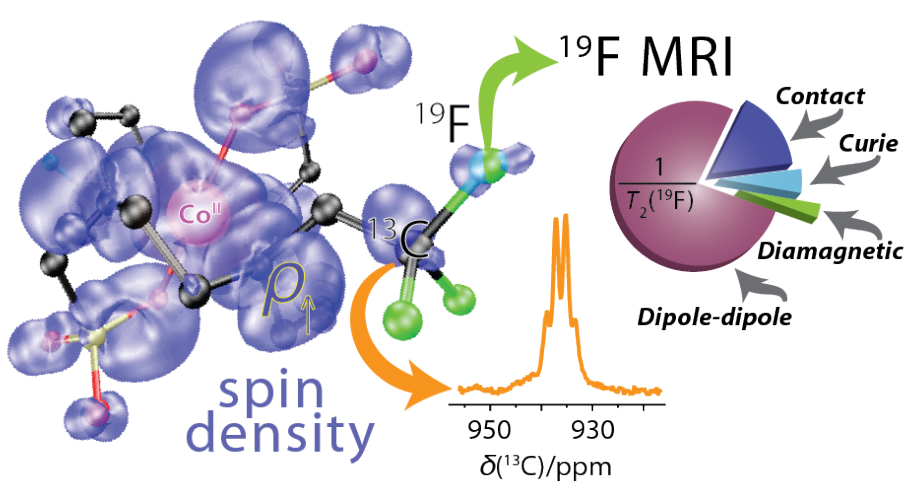

